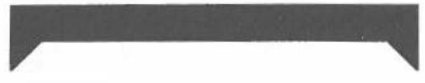

\section{Austria infeliz}

JOSEPH WINKLER, Cementerio de las naranjas amargas. Galaxia Gutenberg / Circulo de lectores, 2008 (Título original: FriedhofderbitterenOrangen. Traducción: Miguel Sáenz).

El Círculo de Lectores, en su sección Galaxia Gutenberg, nos ha regalado a los lectores en castellano que no tenemos la suerte de disfrutar la literatura como debe ser, en su lengua original, la magnífica traducción y versión en lengua española de Miguel Sáenz de la novela autobiográfica (autobiografía novelada, género, por otro lado, tan de vanguardia) del austriaco Joseph Winkler Friedhof der bitteren Orangen, 18 años después de que la Suhrkamp Verlag la diera a conocer a los lectores de lengua alemana. Nos felicitamos -sobre todo, por contar con tan brillante traductor del alemán-y al mismo tiempo nos lamentamos de que las grandes obras de la literatura contemporánea tarden tanto en llegar a los adictos a esa droga tan escasa y oculta tras montañas de publicaciones anodinas o de consumo de masas (la buena literatura debiera ser consumo de masas, si las cosas fueran por donde debieran ir).

Es este Winkler una de esas bestias negras que hacen Antibeimatsliteratur, como lo fuera en la misma Austria Thomas Bernard, o en la literatura actual en castellano Fernando Vallejo y, por supuesto, Jean Genet, de cuya literatura y vida se reconoce admirador y deudor el propio Winkler. Son, por eso, autores de eco controlado (controlado por los guardianes o ayatollás de la Moral, esa horca que a todo creyente espera «en el henil del párroco»del Kamering natal de Joseph Winkler), y para percatarse de ello no hay más que acudir a la web y comprobar cuán poca información nos ofrece sobre un autor que vienepublicando desde 1979 (por cierto, que yo sepa, es Galaxia Gutenberg quien se ha preocupadoanteriormente de dar a conocer a este autor a los leyentes en castellano: Natura Morta y Cuando llegue la bora; sus adictos estamos ansiosos por conocer, entre otras obras suyas, la trilogía carintia Hijo de hombre, El agricultor de Carintia y Lengua materna. Animamos desde aquí a Miguel Sáenz a reparar, tan bellamente como él sabe, este entuerto). No obstante el encono que determinados círculos cercanos a él le profesan, las letras alemanas lo han distinguido recientemente con el prestigioso premio Büchner, que viene a coronar una serie de reconocimientos anteriores, como el Bettina von Arnim o el premio Alfred Döblin. También en España la obra que nos ocupa , El cementerio de las naranjas amargas, ha sido reconocidacomo mejorobra extranjera por el II Premio Lateral de Narrativa 2005.

Lo primero que se me viene a la mente decir a favor del libro en cuestión es que, a pesar de, o tal vez por, su densidad, aparentementecaótica, de sulobreguez asustaviejas, no es un libro que se lea una sola vez. Yo, como lector, me he visto impelido a releerlo, no más llegar a la última frase de sus trescientas ochenta y ocho páginas. Es fascinante seguir al autor-relator por ese reportaje del Horror, dicho así, en mayúsculas, que la ignorancia fanática, llamada por otros experiencia religiosa, que habita entre nos-

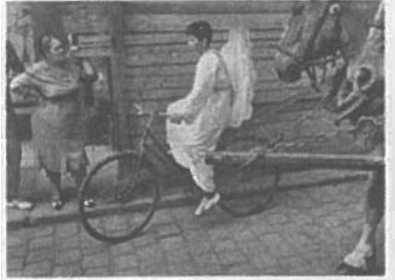

Josel Winfler

Cementerio de las naranjas amargas

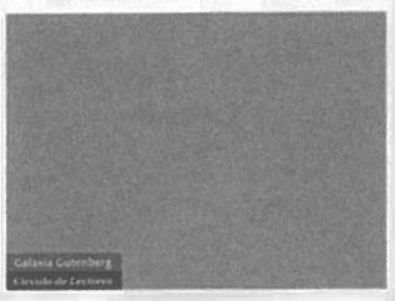

otros y es alentada o estimulada desde los poderes fácticos instalados en las propias mentes crédulas, es capaz de provocar en los más débiles.

Joseph Winkler se distancia en su relato de su Carintia natal, de ese Kamering de poco más de 200 habitantes, construido en forma de cruz (y reconstruido) sobre un antiguo cementerio, $y$, para noatenuar por la lejanía el Horror, se instala para rememorarlo en la misma matriz de la depravación, Roma, e inicia un auténtico tour de los horrores por las vivencias religiosas del sur más profundo, Sicília y Nápoles (por otro lado, no tan alejadas en su atavismo de ese otro sur austriaco que preñó de miedo , y para siempre, al adolescente Joseph, monaguillo y, por lo tanto, descreido). Reportero alucinado, recoge en su cuaderno de viaje en el que están representados los cadáveres resecos y revestidos de los obispos y cardenales del corredor de los sacerdotes de las Catacumbas de los Capuchinos de Palermo, leitmotiv obsesionante de su macabro Poema Sinfónico, una sucesión interminable de imágenes dramáticamente grotescas y certeramente captadas por el lenguaje; enjauladas, en palabra del autor, para de esa forma conjurar el miedo ( «dibujo con mis palabras una jaula en torno al horror, hasta que llega el siguiente horror y quiere despedazarme»). Acude allí donde el horror se manifiesta con un propósito igualmente macabro: para que la constatación de su existencia, la del horror, le permita "disfrutar» en el posterior sueño de recurrentes pesadillas que prolongan, en puro ejercicio de masoquismo, las situaciones extremas vividas en su infancia y adolescencia entre labriegos, duros e insensibles como los terrones de la tierra que riegan con su sudor $y$, en ocasiones frecuentes, con su sangre. Ahí, en ese mundo onírico, que en la novela se entremezcla con la realidad más brutal y, al mismo tiempo, cotidiana, podemos encontrar "cadáveres» para todos los gustos (al igual que en las Catacumbas de Palermo): la rigidez moral llevada hasta el extremo, ejercida con violencia individual y colectiva, que empuja al crimen y a la autodestrucción; la explotación infantil; la homofobia más feroz, que no ofrece a la víctima otra salida que el suicidio o el homicidio aceptado...

Evocamos los seres vivos dentro de un paisaje, y los muertos también. Y para tantos cadáveres se necesita un cementerio, cementerio que el narrador-autor aloja en su cabeza. A él irán a parar los excluidos, las victimas de la maldad, de la maldad religiosa, del fanatismo; los pobres, los sin techo que pululan por la corrupta Roma y por tantas otras Romas segregadoras, levantadas por el egoísmo capitalista; los emigrantes que unen al extrañamiento la humillación del rechazo y el miedo irracional de los bienpensantes; los travestidos y los chaperos. Pero también hay sitio en su cementerio para algunos victimarios, aquellos de los que incluso los confortablemente instalados en la dinámica del odio 
al diferente, al inferior, se avergonzarían: papas malévolos y sus víctimas episcopales, no menos malvadas. Niños, sobre todo niños, cuya fragilidad les hace más vulnerables al fanatismo moral del grupo; débiles paredescontra las que se estrellan y a las que vencen los miedos y supersticiones más ancestrales, pero más arraigadas de lo que a simple vista parece en esta sociedad global, tan asimétrica en su evolución via raciocinio despejador de brumas, propias de la infancia de la Humanidad.

Para quien, como Winkler, ha nacido sobre un cementerio, éste se convierte en el paisaje por excelencia. El que da título a la obra tiene su correlato real en Nápoles, en un parque de naranjos amargos plantados sobre el terreno de un otrora cementerio para excluidos: pobres de solemnidad, vagabundos, extranjeros ... a quienes se arrojaba a fosas comunes, desnudos para aprovechar sus pobres despojos, y arropados únicamente por la inmaculada cal que los desintegraba. Cuando la falsa ética moderna considera la segregación postmortem abominable, la autoridad municipal ordena cubrir el oprobio con un venerable manto vegetal denaranjos amargos y transformarlo en parque público; que el vulgo siguió llamando cementerio, «de las naranjas amargas" como añadido.

Eros y Tánatos, vida y muerte, conviven y convergen en el ser-para-la-muerteque realmente somos. El placer es dolor: gemimoscuandogozamos. Por eso el Horror alterna en el relato con el disfrute inmediato de la carne fácil (o difícil, según se mire), la que a diario se ofrece al consumo en las piazze romanas de nuestras ciudades, con el añadido exótico de la diferencia. Así como la lengua enjaula el miedo y con ello lo conjura, aquí el lenguaje sustituye sabiamente a la imagen pornográfica, e incluso la supera. Si antes nos invitaba a compartir la náusea, ahora Winkler, comoqueriéndonos compensar, nos hace partícipe de sus otros temblores, los del sexo con riesgo, cerrando con ello el círculo del Miedo.

\section{Jessos REY-Joy ח}

\section{Una lectura conmovedora}

ETTYHILLESUM، Una vida conmocionada: Diario 1941-1943. Ed. de J.G. Gaariandt. Trad. del holandésdeManuelSánchez Romero. Revisión deAsunción Sainz Lerchındi. Rubi: Anthropos Editorial, 2007. Colección Memoria rota. Exilios y heterodoxias; 43. 217 págs.

A primera vista, la publicación poco antes del verano en traducción al español de los diarios de la autora holandesa judía Esther Hillesum no debería destacar sobremanera del stream editorial de diarios y autobiografías que abordan los destinos individuales de mujeres damnificadas por el horror nazi en los momentos finales de la Segunda Guerra Mundial. Siguiendo y reviviendo la estela de los famosos diarios de Anna Frank (1947) -que no fueron publicados en su integridad hasta 2001 - otros escritos autobiográficos nacidos de experiencias similares han aparecido en el panorama editorial de los úl timos quince años.

Por no ir demasiadolejos, coetáneo del trágico diario delaadolescente Frank, aunque de reedición de 2002, es Der Schattenmann (diario yapuntes de 1938 a 1945), de Ruth Andreas-Fried- rich, una supuesta integrante de la resistencia alemana, como quieren demostrar sus diarios, quien, sin embargo, no dejó de publicar consejos gimnásticos y cosmética, vida sana, autoayuda y lecciones prácticas para amantes casaderos mientras Hitler marchaba sobre Polonia, declaraba la guerra a EEUU o se sentaba en la conferencia de Wannsee. De guisa análoga es, si se quiere, el diario Tage des Überlebens, de la colaboracio-

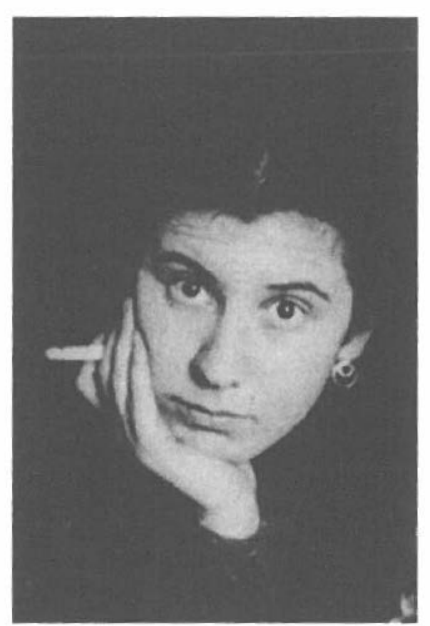

nista nazi y articulista de Das Reich, Margret Bovari, publicado en los sesenta aunque reeditado en 2004 , que refleja la angustia y el terror por el asedio del Berlín de 1945.

Cambian el sesgo de las vivencias -por ese distinto cariz que les da el ser objetivo de la barbarie, más que nada- el testimonio de Lore Walb, a finales de los noventa; o el emocionado relato en primera persona, rematado en 1992, de Christabel Bielenberg, una aristócrata británica que, además de sufrir el intenso bombardeo de Berlín por las tropas aliadas, había sobrevivido a un proceso sumario por su presunta implicación en la preparación delcomplot del general Von Stauffenberg contra el Führer. Para rematar la lista, no puede faltar en este elenco, qué duda cabe, la historia de Eine Frau in Ber- lin, reanimada por el mismísimo Enzensberger en 2003 y de inmenso interés por la estremecedora narración íntima de su anónima protagonista bajo las bombas sobre Berlín, mientras se parapetaba de ellas y del terror a ser una más de las cerca de cien mil violaciones que fueron estimadas durante el avance final de las tropas soviéticas.

Al decir de este repertorio de vidas de mujeres golpeadas por el conflicto bélico, cuesta ver la vida conmocionada de Etty Hillesum como una memoria de guerra al uso. El incuestionable valor testimonial y documental de las narraciones que se acaban de presentar, esa necesaria función de apuntalar los marcos sociales de la memoria de ese holocausto y de esa injusticia histórica es, en el caso del diario de Etty, sólo la primera estación en un texto que trasciende plenamente la anécdota con una teoría vital auténtica e intensa. Ese contexto de la historia y de la persona es en el Diario el sustratonecesario desde el que brota la portentosa reflexión que su protagonista nos presenta acerca de su destino personal en un mundo que ha devenido en poco tiempoconvulso y obsceno.

Ese mundo de Etty desde el que nos escribe es el de la Holanda ocupada sin demasiada resistencia por las tropas alemanas desde mayo de 1940. Ya es conocido que desde octubre de ese mismo año, las autoridades fascistas alemanas aplican en Holanda lo que buena parte de las potencias europeas ya había venido ensayando con éxito desde la época colonial: el control social a través de la segregación racial y étnica indiscriminada, como da prueba la implantación belga del «carnet étnico" en 1934 y sus consecuencias en la vida civil de la Ruanda de nuestros días. Estas medidas marcan a la 
comunidad judía, en un compás in crescendo perfectamente planificado, los pasos de su vía crucis hacia la solución final: la deportación de los miembros de esta comunidad a los campos de concentración de Westerbok y Ausschwitz. Etty refleja en su diario, con dosis de naturalidad forzada y estupor a partes iguales, como también lo han reflejado sus cartas -publicadas en traducción española por Anthropos en 2001la perversión progresiva de la vida pública de esos años centrales de la Segunda Guerra Mundial en el Ámsterdam-Zuid, donde ella vive, y de Deventer, donde residen sus padres.

La convivencia con el temor certero a lo terrible en una normalidad buscada y fingida, sórdida e insoportable, cada día más angosta, es la base de reflexión de Etty sobre la que articula un discurso de preparación a lo inexorable. Como cuando refiere cómo oye a una madre reprender a su hijo: "si no te comes el pan, te irás solo en el tren". Un proceso de interiorización de lo aberrante que le alcanza a ella misma cuando cuenta que el 25 de febrero de 1942 se ha cortado las uñas de los pies, se ha bebido una taza de auténtico cacao Van Hout y ha comido plácidamente pan con mantequilla y miel junto a la chimenea, antes de dirigirse a uno de los interrogatorios habituales ante la GESTAPO. Lo inexorable es el exterminio decidido y decretado de la comunidad de judíos amsterdamesa. Sobre todo, tras la firme determinación de la autora de los nueve cuadernos de rayas azules de permanecer junto a los suyos renunciando a los privilegios que le confiere su propio vínculo con el Consejo Judío de Ámsterdam, su relación con la élite culturalholandesa y el estatus de su hermano Micha co- mo «judío de la cultura». La hora final de la familia Hillesum advendrá el 30 de noviembre de 1943 en Ausschwitz.

Pese a lo penoso e insufrible de la situación, de las profundas y desgarradas quiebras de la tragedia de Etty, el relato entero se abre ante nosotros como una flor de otoño. Una flor que madura precoz para ofrecer la dimensión más franca y magnánima de toda una vida por vivir condensada en estos cortos años de espera angustiosa y atribulada. Resulta, así, un verdadero placer -no exento del pudor que causa una confesión íntima ajena- hojear sus páginas y descubrir cómo conviven en ellas, en un mismo espacio narrativo, la consciencia clara de su destino, en el estupor por el asesinato de seres reales, cotidianos, como Samuel Loo, dueño de la librería Cultura, o el anciano profesor Jan Romein, al tiempo que se retrata la dulce inocencia de una veinteañera entregada día tras día a la amistad de tardes enteras de café y charla con Liesl, Max o Tide sobre Rilke o sobre la literatura rusa, así como a una profunda relación de amor con quien será, a la postre, su paz y su bálsamo, el psicoquirólogo alemán Julius Spier ("me siento como si ya hubiera amado lo suficiente»).

El fruto de estas intensas experiencias, a pesar de todo, no se manifiesta en forma de lamento desesperado y mórbido, sinoque sobrevuela la anécdota, siempre tan real como reductora, para sustanciarse, como ya se ha dicho antes, en una teoría vital superadora y universal. Esta teoría viaja desdeuna voluntad de saber ( "quiero conocer este siglo, desde dentro y desde fuera") limpia de cualquier implicación de poder:

(...) Pero, Señor, dame antes sabiduría que conocimiento. O mejor dicho, sólo el conocimiento que lleva a la sabiduría hace que una persona como yo sea feliz, no al conocimiento que signifique poder

para reposar en una pesada lasitud vital ( «me parece más fácil morir que seguir viviendo»). Y luego bramar en la rabia y el rencor, vecinos naturales de la frustración y la agonía. Por encima de ellas, pura pulsión de supervivencia, se impondrá la catarsis:

Ahi está nuevamente el árbol; el árbol que podría escribir mi biografía. Y aún así ya no es el mismo árbol, ¿o es que sólo me lo parece porque ya no soy la misma persona?

Llega aquí el momento, a mi entender, más puro y delicado del relato. La despedida irremisible de un mundo que ha cambiado vertiginosamente. Merece la pena leerlo en toda su extensión, con el tiempo y la calma necesarios. El discurso se estiliza en progresión y va quedando limpio de todo aquello que le resulta innecesario:

(...) hay que olvidarse de palabras como Dios y muerte, sufrimiento y eternidad; ser de nuevo sencillo y sin palabras como el grano que crece o la lluvia que cae. Sólo hay que ser.

Es la preparación para el sacrificio, para la expiación. Para Etty, un pago justo si supone tener frente a sí y entender la misión que cada individuo tiene para su existencia, para el de la humanidad entera:

Si supiera, si supiera muy claramente que iba a morir la semana que viene, aun así sería capaz de permanecer toda la semana ante mi escritorio y seguir estudiando con toda la tranquilidad del mundo, sin que eso fuera una huida. Ahora sé que la vida y la muerte están unidas, que tienen un mismo sentido.

Un sentido que se glosa en "salvar un pedazo de alma intacto a pesar de todo" en un itinerario fijado antes de nosotros mismos, porque

Cuando la araña teje su red, ¿no traza primero los hilos principales por los que luego desciende ella misma? La arteria principal de una vida va por delante de mi y ha ingresado en otro mundo.

En la teoría de Etty, en suma, el amor es el único camino posible (¿posible?) hacia la paz:

La paz sólo puede convertirse en una paz real más adelante, cuando cada individuo la encuentre en si mismo, extermine y venza el odio hacia los demás, da igual de qué raza o pueblo, $y$ to transforme en algo que ya no sea odio, sino tal vez incluso amor. Pero aún asi eso sea exigir demasiado. Y aún así es la única solución.

Porque la paz no es otra cosa que la expresión colectiva de la liberación del individuo frente al mandato externo de su destrucción mental, de su aniquilación espiritual, de su expulsión de la condición humana, que se alcanza desde una profunda resistencia y transformación interior. Etty converge, así, en el pensamiento de otros intelectuales víctimas del holocausto, como el italiano Primo Levi (suicidio en 1987), el premio Nobel húngaro Imre Kertész, el polaco Tadeusz Borowski (suicidio en 1951), el escritor y ex ministro de cultura español Jorge Semprún, el escritor austría co Jean Améry (suicidio en 1975), la escritora francesa Charlotte Delbo, o el filósofo de origen lituano Emmanuel Lèvinas. Este último, por ejemplo, en su Humanismo del otro hombre (1972), lo resume en palabras que reverberan las de Etty: “(...) Mandar es hacer la voluntad de aquel que obede- 
ce", porque «la voluntad no puede recibir una orden de otra voluntad más que si encuentra dicha orden en sí misma».

Por último, una nota breve sobre la traducción. El texto se presentacomotraducción española del holandés de Manuel Sánchez Romero, con revisión de Asunción Sainz Lerchundi, compañeros ambos del departamento hispalense de Filología Alemana. En tanto resultado final, como Translat, merece ser reconocida como una labor esforzada y conseguida que desemboca en un texto ágil y bien escrito. Ello teniendo en cuenta las dificultades inherentes a una obra original no concebida para su publicación, dificultades que he tenido oportunidad de vislumbrar durante su proceso en las palabras de sus propios intérpretes. Su cuidada labor y el empeño de su editor, la casa barcelonesa Anthropos, parecen cumplir, en fin, la voluntad de Etty: « ser fiel a cada sentimiento, a cada pensamiento que haya empezado a germinar».

\section{PícToR Boprepo}

\section{$\longrightarrow$ \\ El Observador y otros relatos}

PABLO LEVY Der Beobachter und andere Erzählungen, introducción, coordınación y edición de Anke Berns Universidad de Sevilla, Colección de Bolsillo.

La editora del volumen que aquí se presenta, Anke Berns, profesora del 1996 del Área de Alemán de la Universidad de Cá- dizy, a su vez, profesora del Máster en Traducción de Textos Específicos, Interpretación y Doblaje de las Lenguas Española y Alemana que se imparte desde el año 2000 en la Universidad de Sevilla, ha reunido a un grupo de cinco traductores bilingües para dar a conocer por primera vez al lector alemán y español la obra narrativa del autor argentino Pablo Levy.

Esta colección bilingüe de 29 relatos es sorprendente por la novedad de su perspectiva, su hábil prosa y el ingenioso manejo del tour de force (estrategia predilecta de Guy de Maupassant y O'Henry) que a veces nos sorprende y otras nos lleva a la revelación de esa dimensión humana que se escapa de la rutina abriéndonos un mundo más profundo y más real. Es de notar que el primer libro de Levy haya sido publicado en versión bilingüe, español en una página con la traducción al ale mán en la página que la enfrenta. Las traducciones fueron realizadas bajo la coordinación de Anke Berns por varios traductores en conjunción con Levy, y dan a ésta primera obra del autor un relieve internacional, sirviendo de puente literario entre una y otra cultura.

Es apropiado el título de "El observador" que ha dado el autor Pablo Levy a su primer libro de ficción, porque cuando el lector aborda los cuentos siente que observa esa experiencia en particular o comparte la mira desde la cual Levy abre la ventana para contemplar una vivencia que, si bien es individual, por su verdad existencial nos toca de cerca de todos. Y no olvidemos que el observar no es una actividad neutra sino que implica todo un Weltanschauung, una visióndelmundo cultural del cual proviene. En el caso de los relatos de Levy, ese mundo es urbanoy muy espe-

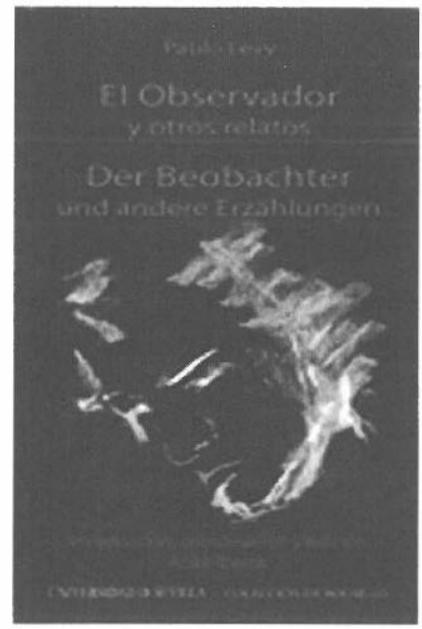

cíficamente Argentino, pero no por eso se encasilla en lo regional sino que parte de lo conocido para abordar temas y situaciones de interés universal.

El cuento «El resto es historia", por ejemplo, parece relatar una noche cualquiera de sexo entre un hombre y una mujer que encuentra en un bar. Pero en un insinuante crescendo, el lector entendido en tango comienza a sospechar que esa historia ya la escuchó en otro lado. El final sorprende porque se reconoce claramente la alusión a otro texto del mundo milonguero. Sin embar go, para quien no conozca el tango, el cuento cobra un significado más directo, el de la lujuria pasajera.

El tango aparece en forma frontal en el cuento "Instrucciones para bailar el tango". Esta joyita de relatoesuna parodia de las posturas y las actitudes de los milongueros porteños que tanto "adoptan una cara de sufrimiento controlado" o dejan caer una furtiva lágrima al escuchar las melodramáticas cursilerías de las letras del tango.

Otrocuento de temática sensual es «Dolores». El protagonista es un magistral e hierático bailarín que se ve en un apuro cuando su pareja se tuerce el tobillo horas antes de la función. Una joven suplente debe to- mar su lugar y todos temen la reacción del bailarín. El desenlace del cuento sorprende por su original combinación de humor y sensualidad.

El cuento "El hincha» tiene de protagonista un fanático del fútbol cuya pasión por su equipo predilecto es una obsesión más fuerte aún que la responsabilidad por su familia.

El fanatismo irracional del hincha termina determinando tanto su vida como su muerte. Reconocemos en este personaje no sólo al fanático del fútbol, sino también a todo individuo que pierde su norte para dejarse llevar por una obsesión, por más banal o profunda que sea.

No faltan tampoco cuentos que pertenecen a un género que está entre lo fantástico y lo ilusorio, como "La curiosa historia del pintor y la cuentista». Este relato describe a un pintor cuyos modelos yuedaban eternizados en sus cuadros pero al poco tiempo morían, evocando así un dilema de tipo Dorian Gray, pero con sabor a pueblo argentino.

También hay cuentos que si bien entretienen, sirven a la vez de revelaciones o de pequeñas epifanías sobre el sentido de la vida y el ser humano que transita por ella.

Por ejemplo, "La rutina» se trata de un director de teatro que rememora la relación pasional que se dio entre los dos actores que una vez convocara para los papeles de Romeo y Julieta. La fugacidad del amor de los jóvenes es contrastada con el recuerdo del director que perdura a través del tiempo, sugiriendo que en la edad madura se comprende que el amor merece la eternidad.

En "La mesa» Levy aborda el tema de la vejez y la soledad que conlleva sobrevivir mientras nuestros seres más queridos mueren dejándonos atrás. 
Pero uno de los relatos que más provocan reflexión tal vez sea el que lleva el título del libro. En "Elobservador» aparece un protagonista inusual que parece estar por encima de los problemas que tanto afectan a los demás. Ni la guerra lo conmueve. El protagonista observa el mundo desde la cima de una montaña "observando la caída del sol con un interés desmedido e ingenuo, como si se tratase de algo fuera de lo común". Es todo su quehacer, observa. Pero en el acto de observar ha penetrado en el profundo misterio de la experiencia humana.

Tal vez sea por eso que Levy ha titulado su imaginativa colección de cuentos «El observador", porque comprende que para vivir y no simplemente existir, hay que tomar conciencia de los valores reales, de lo grande y lo pequeño, de la puesta del sol y el aleteo de un pájaro, sino, todo es puro cuento.

\section{GWENDOLYHDGR}

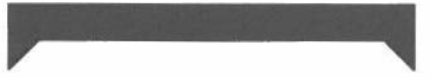

Rescatando el origen de la modernidad

KARL VALENTIN Teatro de cabaret. Edıción de Hiltrud Hengsł y Pedro Alvarez-Osorio. Publicaclones de la Asociación de DIrectores de Escena. Serie Literatura Dramátıca $n^{\circ} 73$, Madrid, 2007, 432 págınas.

A estas alturas de la tecnología cinematográfica nos sería muy extraño retomar la primitiva filmografía muda como medio de expresión contemporánea. Sin embargo, seguimos reconociendo la genialidad de Charlie Chaplin tanto en su faceta de actor cómico co mo de guionista. DeKarl Valentin (1882-1948), autor, productor de cine, comediante ale mán, sucede otro tanto aunque pueda resultar un desconocido para la mayoría del sector teatral.

La Asociación de Directores de Escena (ADE) de España ha dedicado, dentro de su serie Literatura Dramática $n^{\circ} 73$, una publicación al singular cómico de Munich Karl Valentin en un claro ejercicio para recuperar una figura que está en el origen de la modernidad escénica de l a que aún somos deudores. La edición ha corrido a cargo de la filóloga y traductora Hiltrud Hengest y del autor y director de escena Pedro Álvarez-Ossorio. Ambos han conjugado sus respectivos criterios profesionales para realizar una edición que justifica y restituye los valores artísticos del autor muniqués, al tiempo que aporta una serie de textos susceptibles de ser llevados a escena. De este modo, Karl Valentin. Teatro de cabaret recoge una selección significativa de monólogos, escenas y obras de Karl Valentin precedida de una documentada introducción que se hace imprescindible para reconocer al autor bávaro como uno de los artistas más completos de su época, comparable a Chaplin y a Bertolt Brecht con los que se relacionó.

Hengst y Álvarez-Ossorio, en la introducción plantean la hipótesis de "mostrar cómo Valentin emplea tan to formas tradicionales del teatro como formas vanguardistas, adelantándose a su época». Tras mostrar la personalidad y el modelo de espectáculo de K.V., los editores recogen ideas, referencias y opiniones de otros estudiosos ofreciendo «una visión global del arte de este original come-

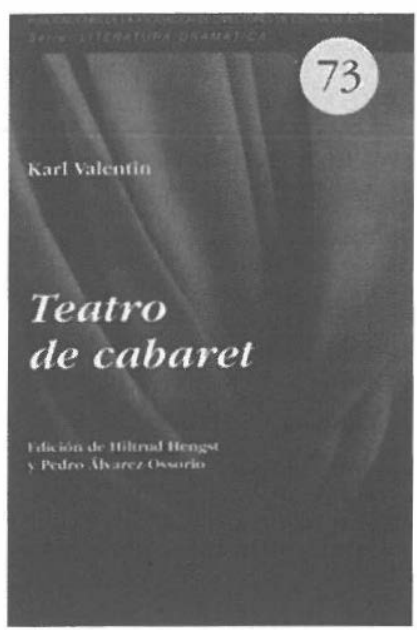

diante", siendo uno de los precursores de la vanguardia del siglo XX. La introducción se completa con los datos biográficos y una útil bibliografía que recogesus ediciones de las obras, su literatura, su filmografía y su discografía.

De entre los textos seleccionados quisiera destacar El confirmado (págs. 338-351) porque quizá signifique la síntesis del humor que desarrolla el autor. En este texto se palpan las imágenes de las películas mudas. Aunque la palabra posee un humor sutil debido al absurdo que plantea, la comicidad está en los movimientos de los personajes que están marcados en las acotaciones y en la deformación grotesca del estrafalario personaje que las protagoniza. En líneas generales, todos los textos de K.V. tienen este sentido de comicidad.

Los textos calificados como Escenas poseenlacomicidad propia del juego del payaso. Me parecen notables las escenas $E l$ atril embrujado (págs. 137-147) que desborda en acción; En la estación (págs. 148-154) la comicidad está en la acotación de la larga cola; Bofetadas (págs. 174-176) y En la tienda de discos (págs. 230-242) tienen la gracia en lo absurdo y tonto del texto con un final desastroso; El encuadernador Wanninger (págs. 182-186) muestra el te- ma de pasar la comunicación de unos a otros hasta agotar al interlocutor; en Peleas con palabras bonitas (págs. 193-196) el humor está en el contraste de la entonación como discusión y las cosas agradables que se dicen los personajes; en Padre $e$ hijo sobre la guerra (págs. 224 229) Karl Valentin plantea el tema de la guerra directamente-en otros textos lo hace con alusiones más o menos veladasdesarrollando razonamientos lógicos, pero la verdadera comicidad radica en el énfasis de la gesticulación.

Con este volumen, aparte de hacer un merecido homenaje al gran comediante Karl Valentin, se recupera y valora una etapa histórica de nuestro teatro contemporáneo.

ManEEL SESMA

\section{rastar \\ Begegnungs- sprache Deutsch}

KRUMM, HANS-JÜRGEN/PORT MANN-TSELIKAS, PAULR. (HrSg.): Begegnungssprache Deutsch-Motivation, Herausforderung, Perspektiven. Schwerpunkt: Sprachenpolitikund fachbezogeneGrundsatzfragen.Studienverlag Innsbrucket al, 2006. ISBN: 3-7065-4200-5 221 Seiten, 18,90 EURO.

Im August 2005 fand im österreichischen Graz die XIII. Internationale Tagung der Deutschlehrerinnen und Deutschlehrer statt, an der auch viele Kolleginnen und Kollegen aus Spanien teilgenommen haben. 28 (von 30) Plenarvorträge wurden im Nachgang in zwei Bänden 
mitdemZieldokumentiert, auch diejenigen über neue Entwicklungen im Fach Deutsch als Fremdsprache zu informieren, die nicht an der Tagung teilnehmen konnten (vgl. S. 8). Im Vorwort des ersten Bandes, mit dessen Besprechung hier begonnen werden soll, erläutern die Herausgeber ihr Vorgehen (S. 7): im ersten Block wurden die Grußworte der UNESCO-Botschafterin für Sprachen Vigdis Finnbogadóttir, die Vorträge der Eröffnungs- und Abschlussveranstaltung, das kulturpolitische Referat von Barbara Frischmuth und die "Grazer Erklärung" als sprachenpolitisches Manifest aufgenommen. Danach folgen, in alphabetischer Reihenfolge der Verfassernamen, die Hauptvorträge, die "das Fach Deutsch als Fremdsprache in seiner Breite, seiner Vielfalt und seiner gleichzeitigen Einheitlichkeit" (S. 7) repräsentieren. Im Folgenden sollen die Beiträge nach thematischen Schwerpunkten besprochen werden.

Die Vorträge der beiden Tagungspräsidenten umreißen den fachlichen Rahmen und die Zielsetzungen der Konferenz sehr gut. Paul R. Portmann-Tselikas erläutert in seinem Beitrag, warum die Tagung unter das Motto "Begegnungssprache Deutsch" gestellt wurde. In einer zusammenwachsenden Weltnehmedie Bedeutung von Sprachen und damit die Wertschätzung von Sprachkenntnissen insgesamt zu. Diese Entwicklung gehe aber gleichzeitig mit einem steigenden Wissen zu Fragen des Sprachenlehrens und -lernens einher, was für Sprachlehrerinnen und-lehrer einegroße professionelleHerausforderung bedeute. Eine der wichtigsten Fragen für Fremdsprachendidaktiker und lehrer laute daher: «Sind wir imstande, neugewonnene Einsichten im eigenen Tun umzusetzen und fruchtbar zu machen" (S. 23)? Lehrkräfte sind auf Fort- bildungsangebote angewiesen, um zum einen den lebenslangen Lernprozess ihrer Lerner begleiten zu können und zum anderen "gute Botschafter der Sprache" (S. 26) zu sein. Für das Gelingen dieser Bemühungen sei ein sprachenpolitisches Umfeld notwendig, wie Hans-Jürgen Krumm in seinem Beitrag deutlich macht. Sprachenlernen habe in erster Linie die "Begegnung zwischen Menschen" (S. 38) zu fördern, die nicht allein durch das Erlernen einer lingua franca erreicht werden könne. Die Entwicklung einer "motivierenden Didaktik der Mehrsprachigkeit und Interkulturalität» (S. 42) sei daher notwendig. Die folgende Grazer Erklärung schließt sich dieser Forderungan und plädiert für die Umsetzung sprachenpolitischer Programme zur Förderung europäischer Mehrsprachigkeit.

Dem Thema Sprachenpolitik widmet sich auch Konrad Ehlich ausführlich. Er untersucht unterschiedliche politische Handlungsweisen im Umgang mit Sprachen und stellt dem nationalsprachlichen ein postnationales Konzept gegenüber, um zu zeigen, wie nationale Ein,Zwei- oder Mehrsprachigkeit gefördert werden könne. Ein wichtiges Instrument europäischer Sprachenpolitik stellt der Gemeinsame Europäische Referenzrahmen dar, der auch in Bezug auf das Testen und Prüfen wichtige Anhaltspunkte liefert, wie Manuela Glaboniat in ihrem Beitrag zeigt. Sie verweistdarauf, dass Testentwicklern und Prüfern zusätzlich ein Handbuch (Manual 2003) für den Einsatz des GER zur Verfügung steht. Allerdings gibt es seit Einführung auch Kritik an diesem Werkzeug, die sich primär auf die starke Vereinheitlichung von Sprachenlernen bezieht. Günther Schneider, der mit dem GER bestens vertraut sein dürfte, diskutiert daher of- fen einige dieser Kritikpunkte, um sie - aus Sicht der "Macher» - zu relativieren bzw. zu entkräften.

Der Beitrag von Rudolf de Cillia trägt dem Tagungsort Rechnung, indem er auf Deutsch als plurizentrische Sprache aufmerksam macht. Dabei geht er auf wichtige Forschungen zu den Varietätenderdeutschen Sprache ein. Dazu zählen das 2003 erschienene Varietätenwörterbuch, und Studien zur Spracheinstellungsforschung, die noch immer eine geringe Sprachloyalität der Deutschschweizer gegenüber dem Schweizerdeutschen und Akzeptanz der Varietäten u.a. bei der Übersetzerausbildung nachweisen (vgl. S. 57). Als Konsequenz für den DaFUnterricht verweist er auf eine von Muhr entwickelte Didaktik des Deutschen als plurizentrische Sprache, die dem Varietätenreichtum stärker Rechnung trage.

Neuere Ansätze der Fremdsprachendidaktik verfolgen im weiteren das Thema Tertiärsprachendidaktik, d.h. Deutsch als dritte Fremdsprache, meist nach Englisch, mit der Skizzierung konkreter Unterrichtsideen von Gerhard Neuner und das Thema Sprachlernberatung. Karin Kleppin plädiert hierbei offen für einen sinnvollen Verbund von Präsenz- und Distanzphasen der Sprachenlernberatung, um "die mit der technischen Entwicklung einhergehende große Euphorie" nicht dem Zufall zu überlassen (S. 107).

Der Aufsatz von Ingrid Gogolin steht unter der generellen Fragestellung, wie es in der Bundesrepublik Deutschland bisher gelungen oder eben nicht gelungen ist, die sprachliche Integration von Kindern mit Migrationshintergrund und damit ihre erfolgreiche Bildungskarriere sicher zu stellen. Sie benennt Gründe für die, in der PISA-Studie attestierte, Bildungsbenachteili- gung dieser Kinder und verweist auf das besondere Förderprogramm FörMig (S. 103f). Claire Kramsch und Alexis Ngatcha schildern in ihren Ausführungen die spezifische Situation des Deutschen in den USA und Afrika. Sie verdeutlichen, dass der Sprachunterricht außerhalb Europas neben dem Erlernen einer Fremdsprache oft ein weiteres Bildungsziel hat, soz.B. die "Begegnung des Lernenden mit einem neuen Selbst " (Kramsch, S. 131) bzw.einer «Existenzanalyse, d.h. auch (...) mentale Rebellion" (Ngatcha, S. 156).

Die Überwindungeuropäischer Grenzen durch die Förderung der Motivation für das Nachbarsprachenlernen und dem offenen Umgang mit Stereotypen (vgl. S. 161) ist das Ziel einer von Albert Raasch entwickelten Didaktik für Grenzregionen und auch Werner Wintersteiner verfolgt diesen Anspruch in der Literaturdidaktik, denn ermeint, dass "wir gerade im DaF-Unterricht nur allzu leicht (...) die kulturelle Differenz zum jeweils Anderen" betonen (S. 210). Das "nationale Paradigma" (S. 211) bei der Auswahl und Behandlung literarischer Themen müsse jedoch von «Grenzüberschreitung ", dass heißt Transkulturalität gekennzeichnet sein. Die physische Überwindung von Grenzen des Sprachenlernens legt Erika Tselikas in ihrem dramapädagogischen Ansatz zum «Einsatz des Mediums Theater im Klassenzimmer" (S. 203) dar.

Letztlich widmet sich der Beitrag von Ingrid Schwerdtfeger dem in kulturellen Erinnerungsprozessen entstandenen "Mythos Lehrer" (S. 183). Sie benennt «zentrale Merkmale einer Person", die Unterricht "erfolgreich werden lassen oder zumScheitern bringen » (S. 191) kann und stellt die Herausforderungen, denen ein Lehrer begegnet unter den Leitsatz «Ethik des Lehrens". Damit ist sie bei 
derFigur angekommen, die bei einer internationalen Deutschlehrertagung ebenso wie der $\mathrm{Ge}$ genstand der Lehre selbst im Mittelpunkt stehen sollte.

\section{SPANIIL}

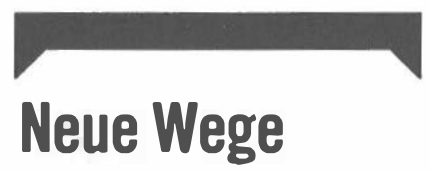

KRUMM, HANS-JÜRGEN/PORT MANN-TSELIKAS, PAUL $R$. (Hrsg.): Innovationen - Neue Wege im Deutschunterricht. Osterreichische Beiträge zu Deutsch als Fremdsprache 9/2005.

Studienverlag Innsbruck et al, 2006. ISBN:3-7065-4201-2,275 Seiten, 26,90 EURO.

Der zweite Band der Tagungsdokumentation zur Internationalen Deutschlehrertagung hat das Ziel, ein Bild dessen zu zeichnen, "was heute im Fach diskutiert wird" (Band 1, S. 7). Dazu gehören die Themen kognitive Linguistik, Spracherwerbstheorie, diesprachwissenschaftliche Analyse des aktuellen Deutsch, der Einsatz neuer Medien und neue Konzepte der Landeskunde bzw. Kulturstudien. Außerdem werden, wie in der Zeitschrift Theorie und Pra$x$ is üblich, ein theoretischer Beitrag der österreichischen DaFForschung und drei Berichte zum Aspekt der "Beziehungen zwischen Österreich und der Auslandsgermanistik» (S. 10) der Österreich-Kooperation aufgenommen.

Einen guten Überblick über den aktuellen Stand der Spracherwerbstheorien gibteinführend Renate A. Schulz. Dabei geht sie den immer wieder kehrendenFragen der Fremdsprachendidaktik nach, ob das Alter den Sprachlernprozess beeinflusse, warum bestimmte grammatische Strukturen leichter als an- dere zu lernen seien, ob der $\mathrm{Er}$ werb einer Fremdsprache dem der Muttersprache ähnele und ob diese interferiere (vgl. S.11). Mithilfe der Forschungsergebnisse aus linguistischen, kognitiv-psycholinguistischen, interaktiven und soziokulturell-soziolinguistischen Ansätzen werden einige Antworten gegeben, um pädagogische Implikationen abzul eiten. Hans Barkowski vertieft in seinem Artikel den theoretischen Ansatz des Konnektivismus und verbindet ihn mit dem Words-and-Rules-Konzept, um aufzuzeigen, dass Sprachverarbeitung "individuell konstruiert" erfolgt (S. 39). Auch Gerard Westhoff leitet a us der kognitiven Psychologie ab, dass die «Identifikation und Speicherung von Information ein aktiver, konstruktiver Prozess ist" (S. 59), weshalb der Formulierung von Lernaufgaben große Beachtung geschenkt werden müsse. Nach der Multi-Merkmal-Hypothese lassen sich Kriterien für effiziente Aufgaben bestimmen. Claudia Riemer wendet sich zudem dem Thema zu, welchen Einfluss der Faktor Motivation auf den Spracherwerb habe. Dazu skizziert sie aus einem Forschungsprojekt Voranalysen aus zehn Ländern, in denen DaF-Lernende in Sprachlernbiographien begründen, wa rum sie Deutsch lernen (S. 47). Erste Ergebnisse weisen für Spanien nach, dass Deutsch vor allem aufgrund von Reise-, Kontakt- und Bildungsmotiven gelernt und fürden ausgeübten Beruf nützlich eingeschätzt wird (S. 50/51).

Aktuelle Entwicklungen der deutschen Gegenwartssprache beschreiben die Aufsätze von Ursula Hirschfeld zur Aussprache, wobei sie neben den Aussprachestandards Deutschlands, Österreichs und der Schweiz im rezeptiven Bereich auch für die Behandlung phonostilistischer, emotionaler sowie individueller
Varianten (vgl. 80) plädiert und Rainer Bohn zurFrage, wie man im Deutschunterricht auf Veränderungen in der Sprache eingehen sollte. Eingroßer Themenblock in seinem Artikel widmet sich den Anglizismen, die vor allem im Fortgeschrittenenunterricht "deutlicher zu thematisieren" seien (S. 89). Außerdem beschreibt der Autor Modifikationen im Bereich der Grammatik, die in erster Linie die Stellung des finiten Verbs in bestimmten Nebensätzen (z.B. weil) und die Aufhebung der Satzklammer (S. 93), besonders im mündlichen Bereich, betreffen. Hier bieten u.a. elektronische Sprachkorpora, wie sie von Tomás Kása für den DaF-Unterricht besprochen werden, eine Hilfe. Vida Jesencek betontdie Notwendigkeit der Behandlungvon Phrasemen ab der ersten Stunde des Deutschunterrichts, da sie den "Normalfall der geschriebenen und gesprochenen Sprachverwendung"' (S. 118) bedeuten und zu den "sprachlichen Universalien» (S. 119) gehören.

Die beiden folgenden Beiträge beschäftigen sich mit dem Einsatz neuer Medien im Unterricht. Jörg Roche richtet seine Ausführungen nach der Fragestellung aus, was «bestimmte Medien in einer bestimmten Situation besser als andere's (S. 131) können. Es geht ihm dabei nicht um den blinden Einsatz von Computer und Internet im Unterricht, sondern um den funktionalen Mehrwert der neuen Medien wie administrative Aspekte, Computer und Internet als digitale Arbeits- und Lernwerkzeuge sowie das didaktische Potenzial neuer Medien zur Visualisierung von Lerninhalten. Dietmar Rösler geht noch einen Schritt weiter, in dem er Funktion und Gestalt eines neuen Typs von Lehrmaterialien zwischen Printversion und Online-Angebot verortet. So unterbreitet erkonkrete Vor- schläge, wie nicht nur zusätzliches Übungsmaterial onlinegestellt, sondern beispielsweise Glossare oder Lehrerhandbücher interaktivgestaltet werden könnten, um so ein "Lehrwerk on demand" (S. 151) zu kreieren, das einerseits der Heterogenität der Lerner (Vorkenntnisse, Lernstile, Region) als auch Lehrer (Berufserfahrung, Persönlichkeit) gerecht werden würde. Für ähnlich viel Kreativität und Phantasie im Fremdsprachenunterricht wirbt Roland Fischer in seinem Aufsatz zum Thema Autonomie. "Sie ist tot, noch ehe sie so richtig begonnen hat" (S. 155), resümiert er zu Beginn, um im folgendenein Lernszena rio zu entwerfen, das er "eingebettete Autonomie» (S. 162) nennt, d.h. Plenar-, Individual- und Beratungsphasen gleichermaßen beinhaltet. Der kulturwissenschaftliche Beitrag von Claus Altmayer in diesem Band verdeutlicht eindringlich die Notwendigkeit, Landeskunde auf eine (kultur)wissenschaftliche Basis zu stellen, um sowohl die Ausbildung von Lehrkräften für Landeskunde-Unterricht als auch diesen selbst zu qualifizieren. «Kulturspezifisches Wissen" (S. 195) kann demnach nicht nur durch Fakten, aber auch nicht den beliebigen Transfer von Inhalten aus den Bezugswissenschaften wie der Politik- oder Geschichtswissenschaft erfolgen.

Die folgenden Arbeiten setzen sich mit Bemühungen zur sprachlichen Integration von Kindern nichtdeutscher Muttersprache in das deutsche Schulsystem auseinander. Zuerst stellt Ingelore Oomen-Welke die Ergebnisse einer Bef ragung von zweisprachigen Eltern nichtdeutscher Erstsprache in Freiburg vor, um daraus Schlussfolgerungen für die Gestaltung der Sprach- und Orientierungskurse für Zuwanderer in Österreich (seit 2003) und 
Deutschland (seit 2005) zu ziehen und bereits ab dem Kindergarten ein integriertes Lernen einzufordern. Zweitsprachenlernende können sich in Alltagssituationen sehr gut verständigen, für ihren schulischen Erfolg ist jedoch eine Textkompetenz Bedingung, deren Beurteilung durch Indikatoren von Sabine Schmölzer-Eibingen in ihrer Studie vorgestell twerden. Im weiteren weist sie verschiedeneStadien der Textkompetenz aus, um schließlich ein didaktisches Konzept zur Förderung der Textkompetenz im Unterricht zu skizzieren. Diesem 3-Phasen-Modell liegt ein konstruktivistisches Lernkonzept zugrunde und beinhal tet einePhaseder Wissensaktivierung, der Arbeit am Text und schließlich die Texttransformation. Der Arbeit mit literarischen Texten und zwar im besonderen mit der Gattung Märchen widmet sich Swantje Ehlers. Sie geht der Frage nach, warum sowohl in verschiedenen Bild-Tonmedien (z.B. Walt Disney-Filmen) als auch in der Literat ur (z.B. Grass, Kunert) immer wieder auf Märchenmotive zurück gegriffen wird. Dazu arbeitetsie "Strategien der medialen und intertextuellen Bearbeitung von Märchen» heraus (S. 208), um diese am Beispiel des Gedichtes von Irmgard Steppuhn "Schneewittchen» zu veranschaulichen. Schließlich widmet sich der letzte Plenarvortrag der IDT von Robert Saxer der Frage der Macht von Sprache. Spracheist demnach Medium von Kultur und Gegenkultur wie er am Beispiel aktueller, österreichischer Zeitungsartikel und Literatur verdeutlicht und auf ihre sprachdidaktische Relevanz verweist. Eine beigefügte Literaturliste dient dem Ziel, bei den Lernern das "Bewusstsein für länderübergreifende, internationale Entwicklungsstrukturen" zu schärfen (S. 229).

Der zusätzlich in die Dokumentation der Konferenzvor- träge aufgenommene Beitrag von Antonella Nardi zur Frage, ob Kommunikation und Interaktion im Fremdsprachenunterricht in einem besonders engen Zusammenhang stehen, wird letztlich durch den sprachpolitischen Bericht von Arnulf Knafl zur Arbeit der im Studienjahr 2006/2007 im Ausland tätigen 1000 Österreich-Lektoren und den konkreten Erfahrungsberichten der Lektorin in Cork, Irland Barbara Stiller und Beobachtungen zur Nationalismusdebatte inUngarn von Harald Gröller, Lektor der Österreich-Kooperation in Debrecen, ergänzt.

Zusammenfassendkann festgestellt werden, dass der Leser durch die Lektüre beider Tagungsbände nicht nur einen guten Überblick über aktuelle Aspekte des Lehrens und Lernens von Sprachen und hier im besonderen des Deutschen als Fremdsprache, sondern auch viele Anregungen für die Gestaltung eines motivierenden DaFUnterrichts erhält. Man darf daher aufdie Beiträge der nächsten Internationalen Deutschlehrertagung 2009 in Jena/Weimar gespannt sein.

\section{DoRoTTR SPANIEL}

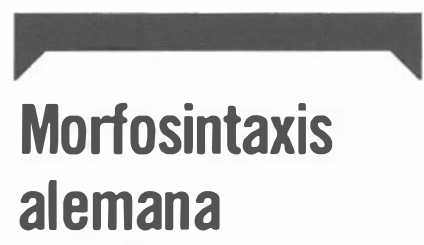

LOPEZ-CAMPOSBODINEAU, RAFAEL (2004). Morfosintaxis alemana. Barcelona: Herder Editorial S.L. 342 pp. ISBN 84-2542372-4

La lengua alemana denota en su estudio un cierto grado de dificultad. Especialmente la gra-

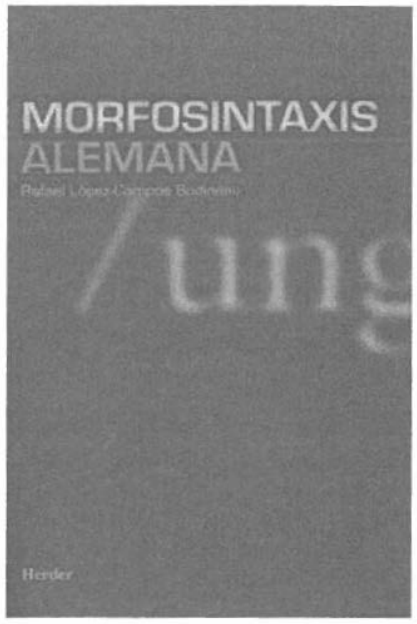

mática, y deforma más concreta la morfología y la sintaxis, resultan ser dos puntos fundamentales -y habitualmente oscuros-para los estudiosos de esta lengua e incluso, en ocasiones, para los profesionales del alemán. Sin embargo, Morfosintaxis alemana de Rafael López-Campos Bodineau resulta ser una obra de consulta imprescindible para estos dos aspectos fundamentales en el aprendizaje y uso correcto de la lengua pues, al conocer todas las dificultades que entraña el alemán y con las que pueden topar los estudiosos o profesionales del alemán, la simplifica con una clara vocación pedagógica.

El presente volumen, que da comienzo con un sucinto «Preliminar» (p.9) escrito por Gerd Wotjak y un "Prólogo" escrito por Luis Acosta (pp. 11-13), se encuentra articulado en torno a dos partes claramente diferenciadas mediante una división sistemática: morfología y sintaxis. En este sentido, cabría destacar muy especialmente la importancia concedida por el autor a la cuestión terminológica y a la definición de los conceptos utilizados, debido a que en algunos casos es en esta obra donde se ha dado por primera vez una traducción orientada al mundo hispanohablante.

La primera parte, “Morfo- logía» (pp. 19-180), consta de cinco capítulos. En el primero de ellos, titulado "Fundamentos de morfología» (pp. 21-63), el autor expone los fundamentos esenciales de la morfología como subdisciplina lingüística dentro del alemán, dando una visióngeneral pero con una amplia bibliografía acerca del morfema como unidad mínima de significado, para pasar a analizar las distintas categorías léxicas de significado de la lengua, centrándose especialmente en el verbo, el sustantivo el adjetivo y el adverbio alemanes, estudiando los tres procesos principales de formación de palabras: derivación, composición y abreviación.

El segundo capítulo, "Morfología verbal» (pp. 64-118), explica de forma clara y precisa que el verbo alemán está formado por un morfema que puede ser alterado mediante tres procesos: aplicación de morfemas ligados de formación mediante los procesos de derivación, la aplicación de o tros morfemas vinculados a través de los procesos de composición o, finalmente, aplicación de los morfemas ligados de relación gracias a la flexión verbal. Estos tres procesos se explican muy detalladamente mediante las gráficas arbóreas, siguiendo el modelo de Tesnière, como medio de exposición, al igual que se aplicarán en capítulos posteriores, pues la ilustración resulta imprescindible para facilitar la comprensión de los distintos procesos morfológicos. Asimismo, los esquemas nocionales y las tablas suponen un paso adelante, aún mayor si cabe, hacia el perfecto aprendizaje dela lengua alemana.

El capítulo tercero, "Morfología nominal» (pp. 119-155), sigue la misma organización que el anterior; puesto que el sustantivo alemán está integrado por un morfema fundamen- 
tal susceptible de ser modificado mediante los procesos de derivación, composición y flexión nominal. Lo mismo ocurre con el capítulo cuarto, "Morfología adjetiva" (pp. 156-167), debido a que el autor, con un fin netamente pedagógico y clarificador, ha preferido seguir una estructura constante dentro de estos tres grupos, aunque el análisis se realice por separado, con el objetivo de facilitar la consulta.

En el capítulo quinto, "Morfología pronominal y determinante" (pp. 168-180), LópezCampos decide abordar de manera simultánea la morfología de las categorías pronominal y determinante, siguiendolas teorías de Baerentzen y Eisenberg, debido a la similitud formal que ambas presentan en la gran mayoría de sus variantes. Asimismo, afirma que desde un punto de vista semántico-cognitivo, tanto los determinantes como los pronombres ponen de manifiesto dos funciones: como elementos determinadores y como elementos cuantores. Porconsiguiente, la tipología de los determinantes y de los pronombres está relacionada con estas dosfunciones. Propone también tres criterios de clasificación desde un punto de vista estrictamente morfológico: según el tipo de marcación, de morfología o de grado de aplicación. Este apartado termina con las variantes fundamentales entre los pronombres y los determinantes, atendiendo a sus distintos ámbitos de naturaleza (artículo determinando, artículo indeterminando,posesivo, demostrativo,...) y a la singularidad formal del pronombre personal.

La segunda parte, "Sintaxis" (pp. 181-329), comienza por una explicación de la jerarquía y estructuración de la sintaxis alemana, aclarando en primer lugar que la morfología y la sintaxis mantienen una vincu- lación muy clara, debido a que mediante los diversos marcadores morfológicos se delimitan las funciones desempeñadas porcada unidad léxica, grupo oracional o proposición (salvo en el caso, obviamente, de los casos de marcadores cero). Asimismo, el autor establece tres niveles en las relaciones existentes en tre los elementos or acionales, que vienen dados por las tres partes de la oración: sintaxis de componentes, relación entre constituyentes de un mismo grupo oracional; sinta$x$ is de grupos, relación entre distintos grupos oracionales; $y$ sintaxis oracional, relación entre proposiciones. Trasesta clasificación, López-Campos const at a que las distintas partes de la oración dentro de cada uno de los tres ámbitos establecidos no se encuentran a un mismo nivel estructural.

"Sintaxis de componentes" (pp. 191-230), el segundo capítulo deesta segunda parte, ahonda en el estudio de los grupos verbal, nominal, preposicional, adjetivo y adverbial; pues la sintaxis de componentes abarca el estudio de las relaciones entre los componentes de los distintosgrupos oracionales, juntocon el análisis de los órdenes estructural y lineal en el entorno de los citados grupos. Por este motivo, el autor sigue la clasificación Eisenberg acerca del análisis de las relaciones de concordancia sobre las que se asienta la coherencia textual.

El tercer capítulo, "Sintaxis de grupos" (pp. 231-286), recoge los diferentes conceptos fundamentales en que se asientan las relaciones entre los distintosgrupos or acionaleso sintagmas. Los grupos or acionales son delimitados del resto de constituyentes mediante la aplicación de las pruebas de inversión (posibilidad de alterar el orden de los grupos sin necesidad de separar sus miembros) y su- stitución (posibilidad de que los miembros sean sustituidos en su integridad por un elemento anafórico cuya naturaleza -nominal, adjetiva o adverbial- coincide con la de dicho grupo). Cabe destacar en este capítulo el apartado titulado "La cuestión terminológica» (pp.233-236) puesto que, excepto la aposición de la que hay una cierta unanimidad en cuestiones de terminologia, el resto de funciones consideradas en la sintaxis (sujeto, objeto directo, objeto indirecto, objeto en genitivo, complemento preposicional, complemento circunstancial y predicativo) son denominadas de muy diversas maneras. En este apartado el autor muestra, mediante una tabla, el amplio uso que ha hecho de la bibliografía.

El capítulo cuarto, titulado "Sintaxis oracional" (pp. 287 329), se centra en el estudio de las relaciones sintácticas derivadas de la generación de oraciones compuestas a partir de la oración simple, mediante la suma de otra y otras de su misma naturaleza obteniendo oraciones paratácticas o coordinadas, o bien mediante la sustitución de alguno de sus términos por una proposición adicional, mediante alguna conjunción subordinada, para obtener oraciones hipotácticas o subordinadas.

Sigue a este capítulo, por último, una comple ta selección bibliográfica actualizada, «Bibliografíacitada" (pp. 331-342), con todas las obras de referencia que ha empleado el autor para fundamentar sus explicaciones teóricas de la morfología y la sintaxis alemanas.

Si bien el acompañamiento de unos ejercicios prácticos que sirvieran al estudian te de la lengua alemana podría haber sido de gran utilidad con el fin de aplicar la excelente teoría de la obra, no se puede negar que nos encontramos ante una herramienta muy útil de trabajo para los estudiantes y profesionales de esta lengua. Morfosintaxis alemana presenta uno de los modelos de estudio más completos sobre los fundamentos morfosintácticos de esta lengua, con un perfil ampliamente clarificador.

En suma, estamos ante una obra de referencia en el ámbito hispanohablante de la lingüística alemana, con una presentación y visión de conjunto de la morfosintaxis alemana con una gran precisión y claridad. Sin duda, un manual de consulta muy detallado, documentado y con numerosos ejemplos y esquemas de gran utilidad.

CRISTINA HUERTAS AbrLL

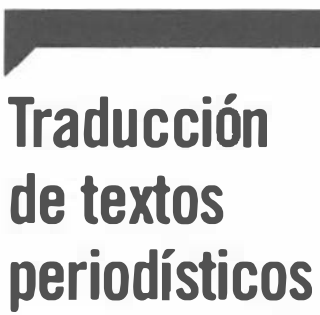

BALBUENA TOREZANO, MARIA DEL CARMEN, La Traducción al Castellano de Textos Periodisticos Alemanes. Introducción Teórica: lenguajes y género periodísticos, (Editorial Bienza, 2007). 196 pp., ISBN: 84-933962-1-4

La presente obra pretende ser una herramienta de referencia para aquellos interesados en la traducción de textos periodísticos desde la lengua alemana a la española. Balbuena se centra especialmente en ofrecer, como bien indica parte del título del libro, una amplia e intensa introducción a los géneros periodísticos, así como a los lenguajes propios del mismo. No obstante, la autora no olvida el perfil traductológico con el que está orientado el libro y vuelca también su atención en la otra 
mitad de éste, la cual consiste en el estudio y explicación de la traducción en los diferentes géneros ya vistos al principio.

A tenor de lo expuesto anteriormente estimo oportuno dividir el estudio y crítica de esta obra en dos grandes partes: la primera sería la versada en la introducción al ámbito periodístico, sus lenguajes y géneros, entre otros; mientras que la segunda sería la parte centrada en la traducción de los diferentes géneros, ya estudiados, del alemán al español.

Balbuena divide en cinco grandes apartados la introducción teórica, los lenguajes y el estudio de los géneros periodísticos de los que presume en el título del libro. El primer apartado es "La información periodística» (pp. 5-7), donde nos hablas sobre qué es el mensaje y la información periodística, así como define el mensaje periodístico y sus peculiaridades. A éste le sigue «El lenguaje periodístico de la $\mathrm{LO}$ y de la LM" (pp. 7-24); la autora habla del lenguaje periodístico como un lenguaje mixto, es decir, integrado por varios lenguajes simples pero también da a conocer una series de características de este tipo de lenguaje en general como la claridad, fluidez, equilibrio, expresividad, etc. También trata las características del lenguaje periodístico en español (al tratarse de la LO en cuestión) y en alemán (como LM). Concluye este apartado hablando sobre el lenguaje periodístico audiovisual y radiofónico. Pienso que ha sido acertado dedicarunapartadoexclusivoal «discurso informativo" (pp. 24-27). En él Balbuena presenta al lector el estudio de tres estilos diferentes de discurso, el estiloinformativo, el editorializante $y$ el ameno. Para un traductor el conocimiento de las lenguas no es suficiente para realizar la labor traductológica, pues debe conocer también la tipología textual a la que se va a enfrentar en la traducción; de ahí que considere de acierto la aparición de este apartado en la obra. El penúltimo apartado de este bloque es el titulado "Géneros del periodismo escrito en la LO y en la LM" (pp. 27-50), tratándose del más extenso de todo el libro, se estudia de forma minuciosa todos y cada uno de losgéneros periodísticos existentesen español y alemán además de darse numerosos ejemplos gráficos extraídos de periódicos de lengua española y alemana para fundamentar con mayor efectividad sus explicaciones. Balbuena nos muestra al principio del apartado una serie de generalidades a tener en cuenta y prosigue clasificando los géneros periodísticos en cuatro grupos generales: "Géneros periodísticos informativos" (la noticia, variedades informativas y el reportaje informativo), "Cćneros periodísticos interpretativos" (el reportaje interpretativo, la crónica y la entrevista), "Géneros periodísticos de opinión" (el artículo de opinión, el artículo editorial, la entrevista de opinión, el comentario o colum na y otros géneros de opinión) y "Géneros periodísticos ambiguos" (las cartas al director y las variedades informativas). Finalmente, el bloque dedicado a la introducción teórica de los lenguajes y géneros periodísticos se concluye por medio del último apartado "Géneros periodísticos en Radio y Televisión” (pp.47-50). Dicho apartado presenta los géneros periodísticos tratados en ambos medios de comunicación (radiofónico y audiovisual respectivamente). Por ello, Balbuena habla de "Géneros periodísticos en Radio» (la noticia radiofónica, el reportaje radiofónico, la crónica radiofónica, el comentario radiofónico y el artículo) y de "Géneros periodísticos en
Televisión" (la noticia televisiva, el reportaje televisivo, la crónica televisiva, el editorial televisivo, el comentario televisivo y la crítica televisiva).

Una vez ha ofrecido una consistente base teórica y fundamentos de estudio y conocimiento del mundo periodístico, Balbuena procede al estudio de la traducción de estos textos del castellano al alemán. Considero por tanto que éste es un bloque nuevo que se caracteriza porque todos sus apartados ofrecen una introducción del género en cuestión, una definición propuesta y un estudio sobre las características y estilo del género en sí además de ofrecer también una traducción resuelta endonde se aplican todos los aspectos vistos en el apartado correspondiente. Comienza el bloque con el apartado "La traducción de la noticia" (pp. 50$63)$ donde cabe destacar las técnicas de realización de este género. El segundo apartado, «La traducción del reportaje» (pp. 63-91) estudia el reportaje interpretativo. Continúa "La traducción de la crónica» (pp. 91 132). En éste apartado Balbuena presenta un amplísimo muestrario de los tipos de crónica existentes: de sucesos, judicial, deportiva, social, de corresponsal fijo en el extranjero, de los corresponsales en provincia, de enviado especial, política y de viajes. La crónica taurina, empero, no se trata aquí, ya que dichogéneronoexiste en la prensa alemana. A continuación, "La traducción de los géneros periodísticos de opinión" (pp. 132-151) en la que, tras tratar con brevedad la historia del articulismo y el columnismo, nos habla sobre el artículo editorial (der Leitartikel), su estructura, estilo y técnica; además de hablarnos sobrelosgéneros afines al mismo en la prensa alemana como der Kommentar, die Glosse y die Kritik. Cierra este apartado con das Essay al que considera una modalidad de artículo de opinión. En el apartado "La traducción de la entrevista" (pp. 151-177) encuentro muy interesante la clasificación de entrevistas que Balbuena of rece: declaraciones de un personaje, entrevista de personalidad, entrevista con fórmulas ya establecidas, entrevista a actores (cine, teatro, etc.) y entrevista a expertos. La autora nos muestra además en este apartado las técnicas de realización de la entrevista y los géneros periodísticos alemanes afines a la entrevista: das Gespräch y das Porträt. Este bloque se cierraconlosapartados correspondientes a "La traducción de un género menor: las cartas al director» (pp. 177-178) y «Latraducción de textos publicitarios» (pp. 178-182) en los que incide especialmente en las características de su lenguaje.

Quedan exentos de los bloques anteriores el úl timo apartado tratado por Balbuena: «El periodismoelecrónico" (pp.182188 ) en el que nos presenta Internet, el periodismo digital: las cadenas televisivas y las noticias 24 horas y el periódico online. Este último apartado, según creo, deja abierta una futura continuación de la misma obra donde puedaestudiarse de forma más profunda y detallada las características propias del periodismo electrónico $y$ digital, el cual es tan novedoso y joven que apenas se puede decir mucho más sobre él.

La obra que nos ofrece María del Carmen Balbuena Torezano cubre un ámbito de la traducción de considerable importancia como es la traducción de textos periodísticos. Ámbito de la traducción que se ve, como muchos otros, eclipsado por el mundo de la traducción de textos científico-técnicos o de textos jurídicos, pero que no por ello merece menor atención o 
interés. El mundo de las Ciencias de la Información y del Periodismoes un pilar fundamental en el proceso de globalización que estamos viviendo y que cada vez más con mayor intensidad forma partede nuestra vida. Por estas razones considero que La traducción al castellano de textos periodisticos alemanes. Introducción teórica: lenguajes y géneros periodísticos es una herramienta imprescindible para todos aquellos estudiosos e interesados de la traducción de textos periodísticos indistintamente sean sus lenguas de trabajo (pues la introducción teórica es común a todo el ámbito periodístico). Además estimo de muy conveniente el uso y manejo de este manual para los alumnos y estudiantes de la Licenciatura en Traducción e Interpretación que cursen asignaturas o materias de traducción de textos periodísticos del castellano o español al alemán.

\section{José M. CAstellaAo MabTTrez}

\section{Filmfestival des Deutschen Films in Madrid}

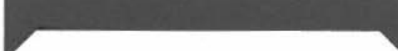

3. bis 8. Juni 2008

Kino Palafox, Cl Luchana, 15

Das Filmfestival des Deutschen Films in Madrid jährte sich dieses Jahr zum zehnten Mal und damit die Möglichkeit, aktuelle deutsche Filme in Originalversion zu sehen und bei vielen dieser Filme sogar den Regisseur oder eineN DarstellerIn über den Film zu befragen. Das ist eine Chance, die man sich

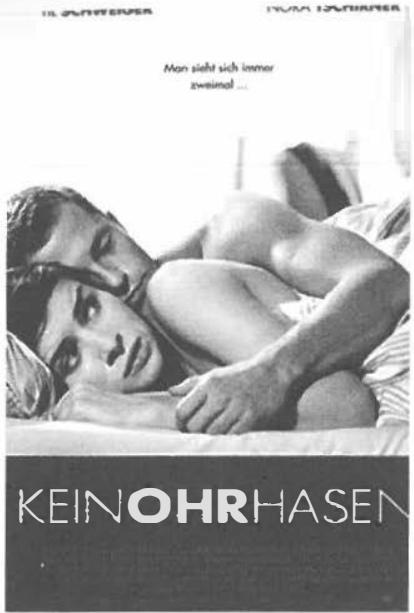

nur ungern entgehen lässt, und ein Genuss der besonderen Art.

Die Filmauswahl war wie in jedem der letzten Jahre vielfältig: sechs Spielfilme, ein Kinderfilm, ein Fernsehfilm, ein Dokumentarfilm, ein Stummfilm, fünf Kurzfilme und acht Filme im Rückblick aus den Editionen der letzten neun Jahre des Festivals boten für jeden Geschmack etwas. Für alle, die bei diesem Festival nicht dabei sein konnten, sollen hier drei der Spielfilme vorgestellt werden, nämlich der Eröffnungsfilm und zwei weitere Filme.

\section{Keinohrhasen (Eröffnungsfilm)}

Regie: 7il Schweiger - Drehbuch: Til Schweiger, Anika Decker - Darsteller: Til Schweiger, Nora Tschirner, Matthias Schweighöfer, Jürgen Vogel - Jahr: 2007

Keinohrhasen ist eine Liebeskomödie im klassischen Stil. Til Schweiger spielt darin einen $\mathrm{Pa}$ parazzo, der in den Tag hinein lebt und nur auf der Suche nach seinen Stories und möglichst vielen One-Night-Stands ist. Beim Versuch, den Heiratsantrag von Wladimir Klitschkoan Yvonne Catterfeld zu fotografieren, fällt er durch das Oberlicht desFestsaalsgenau auf den Tisch der Hauptpersonen. Aufgrund dieses Vorfalls wird er zu 300 Sozialstunden verurteilt.
Diese soll er in einem Kindergarten abarbeiten, wo er auf eine alte Bekannte aus Kindertagen-Anna (Nora Tschirner)trifft, die er damals mit seinen Freunden nur gehänselt und geärgert hatte. Diesmal sitzt sie am längeren Hebel, denn ein Anruf bei seinemBewährungshelfer und Ludo (Til Schweiger) muss ins Gefängnis. Diese Position nutzt sie zunächst voll aus, jedoch kommen sich die beiden mitderZeitund durch die gemeinsame Arbeit mit den Kindem immer näher. Es kommt, wie es kommen muss, und aus dem anfänglichen Hass und der Abneigung wird Liebe, Anna findetendlich das Liebesglück und Ludo hängt seine Vorliebe für One-Night-Stands an den Nagel und gesteht sich selbst und Anna seine neuen Gefühle zu ihr ein.

Neben dieser Haupthandlung werden verschiedene Themen angesprochen, nämlich das Los der Berühmten, ständig von Paparazzi verfolgt zu werden sehr schön ist die Mitwirkung von berühmten Leuten, die sich selbst darstellen, z.B. Jürgen Vogel, Yvonne Catterfeld und Wladimir Klitschko-, die Beziehungen, diezwischen Mann und Frau entstehen, wobei Anna für feste Beziehungen steht und Ludo für flatterhafte OneNight-Stands, und die Frage, wiemanglücklich werden kann, nämlich ob ein anderer einen glücklich machen muss oder ob man aus sich selbst heraus glücklich sein kann.

Die Handlung des Filmes kann auf den ersten Blick langweilig und schnulzig wirken, aber dieser negative Aspekt wird durch sehr witzige Dialoge und Szenen, super (?) Musik und überzeugende Darsteller voll und ganz ausgeglichen, wobeifür meine Begriffe Til Schweiger eher in seiner Rolle als Kindergärtner als in der als Paparazzo überzeugt.
Der Titel "Keinohrhasen" wird übrigens im Film erklärt, warum das aber als Titel über dem ganzen Film steht, wird nicht sehr klar.

Sprachlich betrachtet ist der Film für Deutschlerner besonders gut dazu geeignet, das gesamte deutsche Vokabular von Schimpfwörtern und derben Ausdrücken kennen zu lernen.

Ich kann diesen Film nur empfehlen, allerdings unter der Voraussetzung, dass man dieser Art von Handlung nicht negativ gegenübersteht und sich gerne von witzigen Dialogen mitreißen lässt. Ich habe lange nicht mehr so viel gelacht wie in diesem Film.

\section{Nichts als Gespenster}

Regie und Drehbuch: Martın Gypkens - Darsteller: August Diehl, Stipe Erceg, Fritzi Haberlandt, Wotan Wilke Möhring, Karina Plachetka - Jahr 2007

Der Film Nichts als Gespenster basiert auf fünf Geschichten von Judith Hermann aus ihren Büchern Nichts als Gespenster und Sommerhaus, später. Die

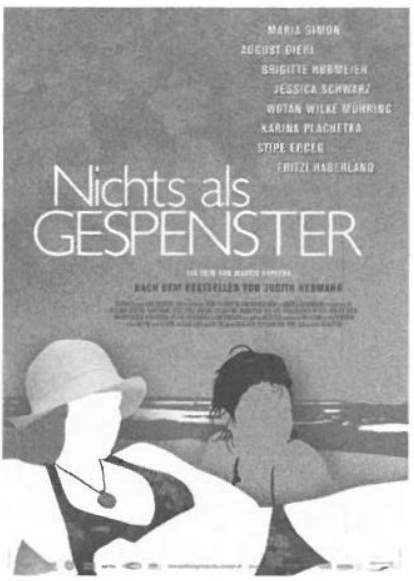

Geschichten spielen an fünf verschiedenen Orten: in Deutschland, Island, Venedig, den USA und Jamaika. An diesen Orten spielen sich fünf unabhängige Geschichten ab, von Menschen auf der Reise und zwischenmenschlichen Beziehungen. Die- 
se Geschichten laufen parallel, sie wechseln sich ständig $a b$ und der Zuschauer muss die einzelnen Puzzleteilezu fünf ganzen Geschichten zusammensetzen. Eine Handlung lässt sich nur zwischen den Zeilen finden, in jedem Fall geht es wie gesagt um zwischenmenschliche Beziehungen, wobei die Dialoge nur sehr kurz oder praktisch nicht vorhanden sind. Das Schweigen herrscht vor. Insgesamt bleibt der Film sehr nah an der literarischen Vorlage. Faszinierend sind die wunderbaren Landschaftsaufnahmen und Stimmungen der einzelnen Orte, die geschickt erzeugt werden und einen auf die Reise mitnehmen.

Obwohl der Film eher langatmig ist, hat man nicht das Gefühl von Langeweile, vielleicht, weil die Geschichten parallel erzählt werden und nicht eine nach der anderen, und weil man von den Landschaftenund Stimmungen vollkommen eingefangen wird. Es entsteht Reiselust.

Empfehlenswert ist dieser Film nur für Liebhaber von schönen Landschaften, in keinem Fall für Liebhaber von Action-Filmen, die zweifellos einschlafen würden.

\section{Beautiful Bitch}

Regie und Drehbuch: Martin TheoKrieger-Darsteller: Katharina Derr, Sina Tkotsch, Patrick von Blume, Lucien Le Rest, Tom Lass - Jahr: 2007

Beautiful Bitch handelt vom rumänischen Straßenmädchen Bica (Katharina Derr), das, angelockt durch Versprechungen des ehemaligen Polizeibeamten Cristu (Patrick von Blum), illegal nach Deutschland reist, um dort als Taschendiebin zu arbeiten. Dort wird sie von ihm mit drei Jungen in einer kleinen Wohnung gehalten und muss täglich 500,- Euro Bargeld oder anderes Diebesgut abliefern. Nach

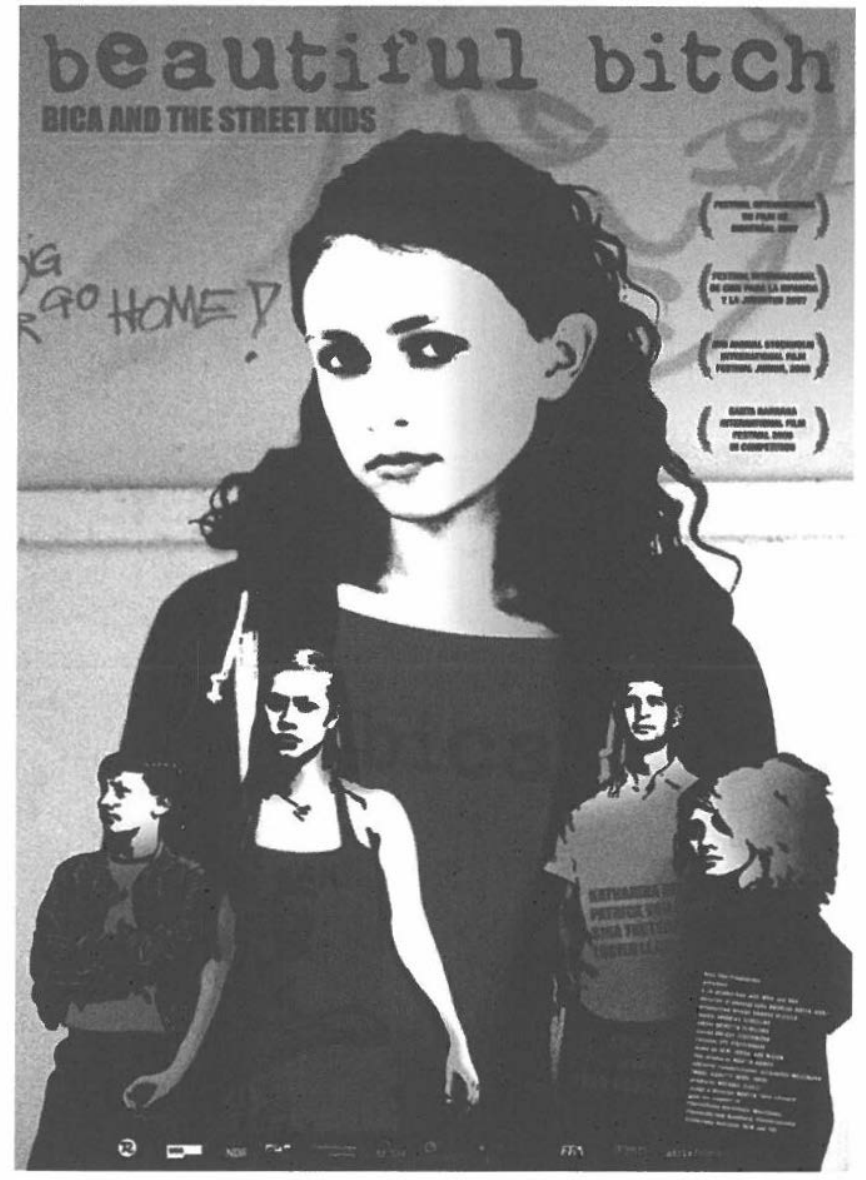

einiger Zeit schließt sie Freundschaft mit der Tochter eines Restaurantbesitzers, dem sie zuvor den Geldbeutel gestohlen hat. Milka (Sina Tkotsch) ist ein Mädchen,dasein normalesTeenager-Leben in der gehobenen Mittelklasse führt, und durchsie erhält Bica einen Einblick in dieses ihr ferne Leben. Ein starker Kontrast dieser Freundschaft liegt darin, dass Milka, die alles hat, was sie braucht -neue Kleider, Make-up, 5 Handys, die Freiheit, zu tun und zu lassen, was sie will, Geld-, sich ständig über ihr schreckliches Lebenund ihre Eltern, die geschieden sind, beklagt. Bica hört sich alles geduldig an, kann dem aber nichts erwidern, weil sie nicht von ihrem wirklichen Leben berichten darf. Aber im Kontrast zu Bicas Situation klingen die Klagen von Milka lächerlich und vollkommen unwichtig. DenSpitznamen Bitch erhält Bica von Milka, da das so ähnlich wie ihr eigentlicher Name klingt. Als Cristu von der Freundschaft der beiden Mädchen erfährt, versuchter diese gewaltsam zu unterbinden, was zur Katastrophe führt.

Der Film ist packend und hält die Spannung von der ersten bis zur letzten Minure. DieGeschichte ist überzeugend, nicht zuletzt wegen der großen schauspielerischen Leistung der Hauptdarstellerin, einer Sibiriendeutschen, die mit 6 Jahren nach Deutschland kam, in ihrer ersten Rolle. Erzählt wird eine fiktive Geschichte, die im realen Ambienteder Kinder, diegezwungen werden, in deutschen Großstädten als Taschendiebe zu arbeiten, angelegt ist. Der Film ist nach zweijähriger Rechercheentstanden und stellt die Situation dieser Kinder überzeugend und gleichzeitigerschreckend dar.

In Bezug auf die Sprache fällt auf, dass das Mädchen aus Ru- mänienakzentrei Deutschspricht, auch in ihrer Heimat Deutsch verwendet, wodurch die Freundschaft mit Milka erst zu Stande kommen kann. Ich gehe davon aus, dass die Sprachbarriere nicht weiter thematisiert werdensoll, um die Geschichte nicht noch komplizierter zu machen.

Interessant ist auch eine Äußerung von Bica über die Verwendung von Sprache. Sie wirft Milka vor: "Du verwendest Wörter wie Messer, du schneidest, schneidest..." Damit bezieht sie sich auf die Tatsache, dass Milka Sprache oft auf verletzende Art und Weise verwendet, vor allem gegenüber ihren Eltern, aber auch mit ihren Freunden, wenn sie sich ärgert oder gekränkt ist.

Auch diesen packenden und gut gemachten Film kann ich sehr empfehlen.

Zusammenfassend lässt sich über das Filmfestival wie in den letzten Jahren auch sagen, dass es ein tolles Ereignis ist, weil es die aktuellen deutschen Kinofilme nach Madrid bringt und die deutsche Filmindustrie bekannt macht, so dass man auch in Spanien zunehmend deutsche Filme sehen kann. Besonders interessant ist, dass bei vielen Filmen Darsteller oder Regisseure anwesend sind und nach der Vorführung Fragen beantworten, wie bei Keinobrhasen die Hauptdarstellerin Nora Tschirner und bei den anderen beiden Filmenjeweils der Regisseur, So hat man Hintergrundinformationen erhalten und wurden die Filme verständlicher. Leider findet das Filmfestival immer am Anfang der Prüfungszeit der Universitäten statt, so dass ein großer Teil des zu erwartenden Publikums keine Zeit für einen Kinobesuch hat.

Ich hoffe, dass dieser Artikel Lust auf mehr gemacht hat, das Festival ist auf jeden Fall einen oder mehrere Besuche wert?

Gisth Romold 


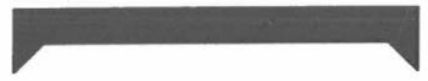

Musik einmal anders - Ein «Gesprächskonzert» von Rolf Kohlrausch

Dieses Jahr durften wir in Málaga ein Frühlings-Präludium der besonderen Arterleben. Das Konzert des hannoverschen Pianisten Rolf Kohlrausch am 12. März im Ámbito Cultural des El Corte Inglés war ein doppelter Genuss: er verwöhnte die Anwesenden nicht nur mit seiner Spielkunst sondern machteauch seinem Engagement als Musikpädagoge alle Ehre. Veranstaltet wurde der Abend vom Andalusischen Germanistenverband AGA über seinen Dachverband FAGE, der eine Tournee durch ganz Spanien ermöglicht hatte, sowie vor Ort von der Asociación Hispano Alemana de Málaga y de la Costa del Sol, AHA.

Diemusikalische Laufbahn von Rolf Kohlrausch begann im Alter von 9 Jahren bei Gertrud Morgenstern-Konwitschny, seine erste Klavierlehrerin und Schwester des berühmten Gewandhaus-Kapellmeisters FranzKonwitschny. Sie erkannte sofort seine besondere Begabung und förderte ihn. Bestimmend für seine musikalische Entwicklung und Inspiration waren jedoch Branka Musulin, bis zu ihrem Tod 1975, und Leonard Hokanson, bei dem er bis 1980 in Frankfurt am Main studierte, wo er sein Diplom als Konzertpianist erhielt. Seitdem hat Kohlrausch zahllose Konzertein ganz Europa gegeben, von Luxemburg bis Italien, von Österreich bis nach Kroatien und Spanien.
Seine zweite Begabung, die der Pädagogik, wurde 1985 mit einem Ruf an die Augsburger Universität honoriert. Hier hat er seinen Klavierstudierenden aus aller Welt den Weg zu den Konzertbühnen in Europa, Amerika, China... eröffnet. Seit 2007 können nun auch die Studierenden in Würzburg seinen persönlichen, engagierten Unterricht erleben.

Das "Frühlingskonzert» wurdedurch die Vorsitzende der Asociación de Germanistas de Andalucía, Prof. Dr. María José Varela eröffnet. Nach der Begrüßung des Vorsitzenden der Asociación Hispano Alemana de Málaga y de la Costa del Sol, Prof. Dr. Enrique Baena, an das Publikum und den anwesenden deutschen Konsul, erfreute uns der Pianist und Professor Rolf Kohlrausch mit einer Auswahl von FranzSchubert (Impromptu As-Dur op. 142,2), Ludwig van Beethoven (Sonate d-moll op. 31,2- *Der Sturm») und, selbstverständlich seinem Lieblingskomponisten Claude Debussy (Children's Corner: Doctor Gradus ad Parnassum • Jimbo's Lullaby - Serenade for the doll - The snow is dancing - The little shepherd - Golliwogg's cake-walk - Rêverie Claire de lune • L'Isle joyeuse).

Bevor der Pianist Rolf Kohlrausch die Stücke mit Hingabe am Klavier zum Leben wiedererweckte, hatte der Professor Kohlrausch das Publikum schon längst in deren Geheimnisse eingeweiht und es in den Bann der in den Noten evozierten Welten gezogen. Mit seinen anregenden Erklärungen über die Autoren und die besonderen Umstände der Stücke brachte Prof. Kohlrausch diese dem Publikum nahe; dabei unterließ er es nicht, die konkreten Notenfolgen oder Passagen, die seine Erklärungen beispielhaft untermauerten, am Klavier zu spielen. Die schon mitgebrachte Er-

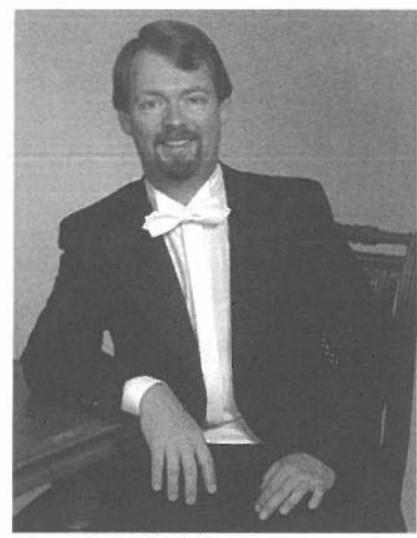

wartungshaltung des anwesenden Publikums wurde in mehrfacher Weise angeregt: zunächst wollte man natürlich die Werke der großen Musiker unter den Händen des deutschen Pianisten hören, dochdurch die Erklärungen war man neugierig auf die Verwirklichung der gehörten Geschichten und Hintergründe in der Musik geworden und hoffte die Entsprechungen in den jeweiligen Passagen heraushören zu können; vor allem aber sehnte sich das Publikum nach der Empfindung der durch die Worte des Professors erweckten Gefühle in der Darbietungdes Pianisten. Und glauben Sie mir, niemand wurde enttäuscht.

Professor Kohlrausch selbst waren seine Erklärungen so wichtig, dass er um einen Dolmetscher gebeten hatte, damit auch das spanische Publikum diesen genau folgen konnte. Nebenbei sei bemerkt, dass diese Ehre und Freude mir zuteil wurde.

Besonders interessant und wichtig erschienen mir seine $\mathrm{Er}$ klärungen (in der Folge frei zitiert) zu Beethovens Der Sturm und zu Debussys Children's Corner. Sicherlich hätten wir ohne sie die Musik Beethovens oder Debussys und die Spielkunst Kohlrauschs auch ausreichend genießen können. Doch hätten wir wohl nicht die Verbindung zwischen Beethovens und Shakespeares "Sturm" erfahren oder warum das Stück «zum Inbegriff musikalischer Dämonie, zum Prototyp aller romantischen Stürme und Leidenschaften" wurde.

Wir wären uns wohl auch nicht de Persiflage des Doctor Gradus ad Panassum bewusst gewesen. Wir hätten uns bei Jimbo's Lullaby wohl vorgestellt, wie ein Kind in den Schlaf besungen wird, nicht aber "Jimbo, den kleinen Stoffelefanten, der zur Gute-Nacht-Geh-Zeremonie für Debussys Tochter gehörte»; und bei den tiefen Tönen des Stücks wäre uns auch entgangen dass «einElefantaus der Sicht eines Kindes etwas Schwerfälliges ist, was sich sinnvoller Weise mit tiefen Tönen darstellen lässt. Man könnte glauben zu hören, wie sich der Elefant träumend hin- und herwälzt und schließlich in den Tiefschlaf sinkt»". Hätten wir ohne Kohlrauschs Erklärungen in der Fröblichen lnsel weine gefühlvolle Transposition dessen, was unsichtbar in der Natur ist ” erlebt? Hätten wir "nicht den äußeren Aufbruch zu neuen Ufern, sondern den individuellen, geistigen, der in diesem Stück dargestellt wird, nicht das Biederedes Watteau-Bildes, sondern die Sehnsucht nach dem ewigen Glück, die im Sinnestaumel sich auflöst ", erkannt? Wohl kaum.

Mit Sicherheit gibt es für den geschulten Liebhaber klassischer Musik Gründe genug, sich an den Stücken der großen Komponisten ohne fremde Kommentare ergötzen zu wollen, das breite Publikum, das sich in Málaga von RolfKohlrausch in Frühlingsstimmung bringen und ergötzen ließ, wird dennoch seine künstlerisch-pädagogische Darbietung begrüßt haben und dürfte jetzt auf seinen nächsten Auftritt in Málaga warten.

Pco. Batez de Agullar Gonzalitl 


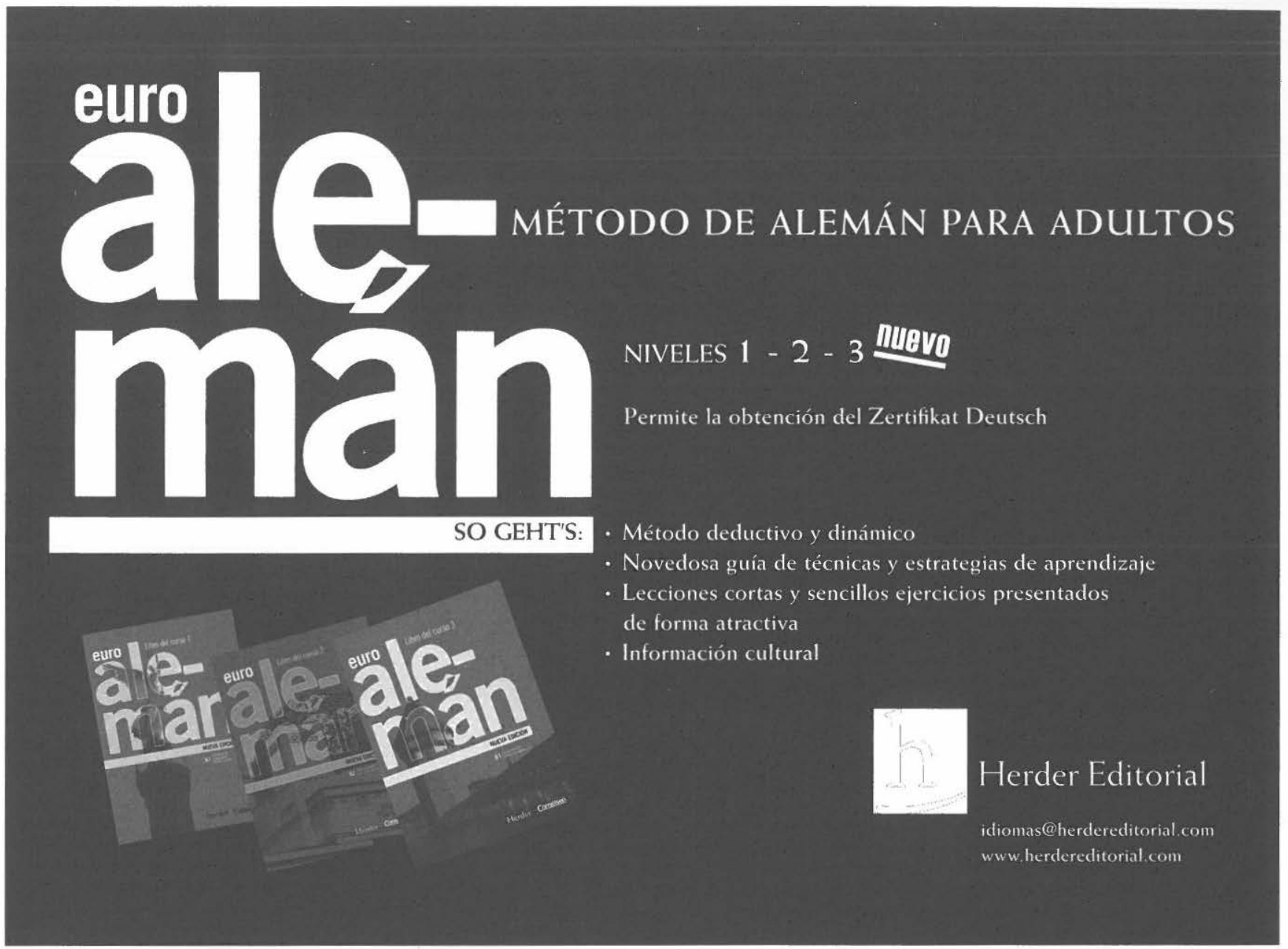

\section{Liebe Leser des mAGAzins}

In unseren Rezensionen wird auf Neuerscheinungen im Bereich der Germanistık verwiesen , vor allem auf Bücher, die für die Forschung, Lehre und Lektüre auf der Iberischen Halbinsel von Bedeutung sind. Das Hauptgewicht liegt dabei auf Texten, die in Spanien erschienen sind, doch sollen auch in den deutschsprachigen Ländern publizierte Bücher besprochen werden. Die Rezensionen sollen vor allem informativ sein und das jeweilige Buch so kur $z$ wie möglich, so klar wie möglich und so präzis wie möglich kritisch analysieren. Die einzelnen Rezensionen können verschiedene Länge haben, sollten sich jedoch an dres Standards halten: Kurzrezensionen sollten nicht mehr als 1000 , mittlere Rezensionen 1800 und lange 2800 Zeichen umfassen. Rezensions sprachen sind Spanisch und Deutsch.

Der Rezensionsteil hat die folgenden Unterkapitel: 1. Literatur und Literatur in Übersetzung

2. Literaturwissenschaft (inklusivealler daraufzu beziehenden Diszipli. nen im Bereich der Theoriediskussion)
3. Sprachwissenschaft (inklusive aller darauf zu be zıehenden Disziplinen wie etwa Sprachphilosophie) 4. DaF

5. Kulturwissenschaft ( $\&$ andeskunde», Geschichte, interkulturalität etc.)

6. Translationswissenschaft

7. Sonstiges

Außerdem zwei besondere literarische Abteilungen: "Klassiker neu gelesen», in der Neues zu für die Literaturgeschichte wichtigen Büchern gesagt oder

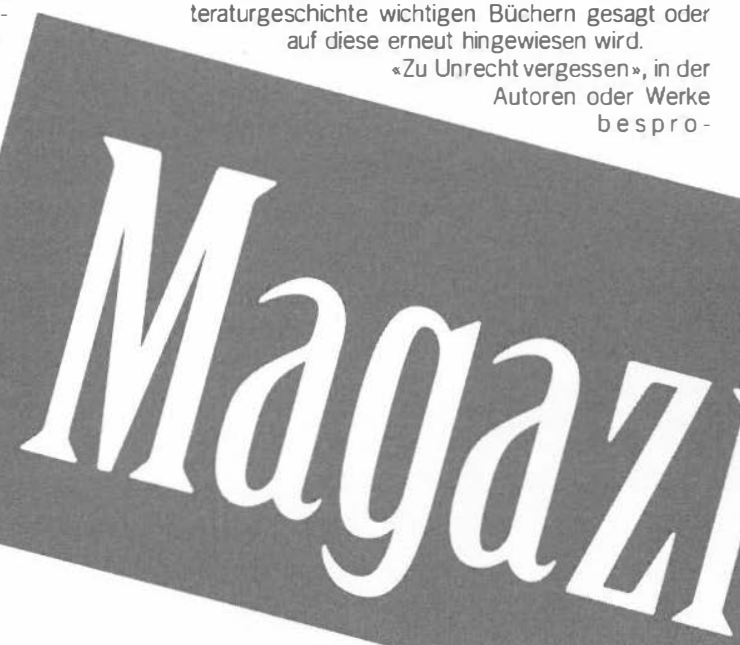

chen werden, die man doch wieder einmal lesen könnte, sollte oder müsste.

Diese beiden Abtellungen sind eher essayistischer Natur, die hier erscheinenden Beiträge können daher durchaus etwas länger sein.

Weiterhin haben wir auch Kritiken neuerer, in Spanien gezeigter deutscher Filme in unseren Rezensionsteil aufgenommen.

Die Mitarbeit steht allen Lesern des mAGAzıns offen, Vorschläge für Rezensionen sind immer willkommen. Wir möchten daher alle Leser einladen, uns über Neuerscheinungen zu informieren; Autoren können uns ihre Bücher schicken, Rezensenten können uns zu besprechende Bücher vorschlagen oder ihre Rezensionen vorschlagen oder ihre Rezensionen
direktan die Redaktionsenden. Die Redaktion behältsichje. doch das Recht vor, Beiträge zu redigieren, zu kürzen oder abzulehnen.

Christoph Enlers ehlers@us.es 


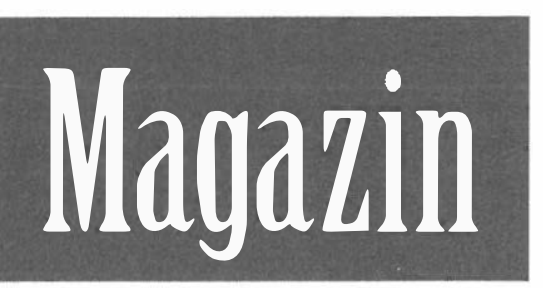

\section{Boletín de inscripción}

Nombre y apellidos

Dirección

\begin{tabular}{ll}
\hline Código Postal & Población \\
\hline Pais & Teléfono \\
\hline E-mail & \\
\hline Lugar de trabajo &
\end{tabular}

Lugar de trabajo

Deseo inscribirme en la Asociación (ver página 84)

Precio de la inscripción: $36,00 €$, Incluye la participación gratuita en las actividades de formación del AGA, tarifas reducidas en las Jornadas Didácticas del Instituto Goethe y el Congreso de la FAGE (Federación de Asociaciones de Germanistas en España, www.fage.es), así como la suscripción a la revista magazín (www.fage.es/aga/magazin 170 18).

Por la presente, autorizo a (indicar Asociación): a cobrarse anualmente, mediante transferencia bancaria, la cantidad de $36 €$ de mi cuenta: Cuenta Corriente / Libreta $n^{\circ}$

Banco / Caja Agencia $n^{0}$ Dirección

Código Postal Población Provincia

Tramitación para la AGA:

Rellenar los datos y firmar este boletín. Entregarlo por una de las siguientes vías:

- Correo ordinario: EOI Cádiz. Departamento de Alemán. Calle Pintor Sorolla, 15. 11010 Cádiz

- Escanear y enviar por e-mail a la dirección jblobato@telefonica.net

Para otra asociación, contactar señas en la página 84

\section{Lugar} Fecha

Firma 


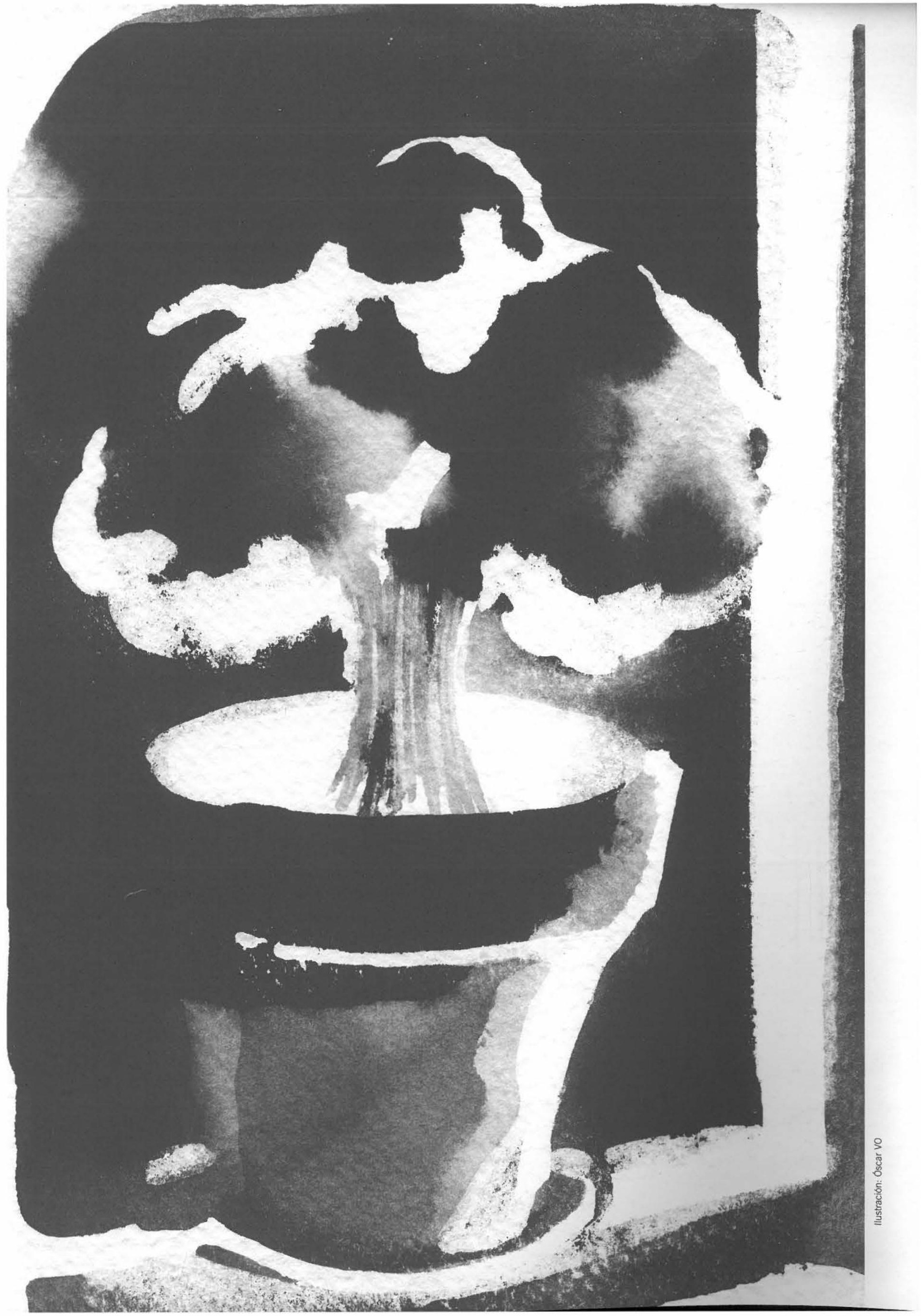


En Noviembre pasado falleció nuestral amiga y companzeral l-tiltrud Hengst, socia fundadora de la Asociación de Ciermanistas de Andalucía $(A(S)$ e incinsable astivista del alemán, no sólo en nuestra Comunidad. Todos los amigos, compañeros o alumnos de allemán que hemos tenido la suerte de que Hiltrud se cruzara en nuestras vidas, queremos expresar muestro profundo agradecimiento) por su trabajo, amistand e inspiración. Somos legión: los colegas del Instituto Sin Isidoro y del Colegio) Macarena (Sevilla), del Departamento de Filología Alcmanas y del Area de Alemán del Instituto de Idiomas de la Universidad de Scvilla, del Colegio Alem ín Allorto Durero, del Centro de Profesores de Sevillar, de los Departamentos de Aleminin de las Escuelas Oficiales de ldiomas y los Centros Bilingies de Alemain de Andalucía, del Instituto Goethe de Madrid y Múnich, de la Asociazción de Germanistas de Andalucía ACiA, de la Federación de Ciermanistas de Espana FAGF... muchísimos comparieros de profesión, que la conocian, aprecciaban y admiraban.

El día del multitudinario entierro, Marite Jiménez escribió descle Hamburgo: "Hay personas que irradian luz allá donde estín y Hiltrud ha sido luz también para mí. No podré estar físicamente mainalna, pero mi ser cstaríi acompaiiando la despedida de nuestra amiga y Maestra con mayúscula. La vida me regaló su companizis, apoyo, guía, alegría...». Otra amigá de la profesión, Beate Kochler, del Instituto Ciocthe del Cairo, escribió que establa compleramente désconsoladis. Y arsi todos.
Hiltrud T. I- lengst Wegmann, geboren am 11. Naii 1948 in Essen, war ganz vicle Dingc. Hhre schier grenzenlose Energic erlaubte es ihr cinfach nicht, sich mit nur ciner Beschaftigung zufrieden zu geben. Sic war I.chrerin, Forscherin, Fortbilderin, Publizistin, Übersetzerin, dameben Ehefrazu und Mutter... man fragte sich immer, was im Himmel, bei all der viclen Arbeit, das Crehcimmis iher Kraft und guten Laune war.

Hiltrud kam 1974 als Deutsch- und Franzijsisch-Lehrerin nach Sevilla, nachdem sic dic Stadt im Laufe ihres Studiums als DAAD-Stipendiattin kennen gelemt hatte. Die dynamische junge Deutsche, Diplom-Romanistin der linken Universität Bochum der Siehziger Jahre, brach schnell veraltete Strukturen auf und brachte frischen Wind in die verstaubten Aulen der Provinzstadt des spiten Frankismus. Zunkichst unterrichtete sic Deutsch und Französisch an verschiedenen Schulen, unter anderen der Deutschen Schule in Sevilla?, bis sie 1986 die erste beantete Deutsch-Lehrerin Andalusiens wurde und ihre Arbeit am Institure Sin Isidoro aufnahm. In einer Zeit, in der Techniken wic (iruphen- oder l'aararbeit, Assoziogramme, (icschichten mit offenem Fnde, Dramatisierung ctcetc. noch lange kein Allgemeingur walren, führte sie dort moderne, kommunikativ orienticre Unterrichtsformen cin.

lhr Engagement kannte keine Girenzen. Sie stiftete zahlireiche Austauschpartnerschaften mit Schulen in I Jeutschland, die Ichenslange lmpulse gegchen haben. Sic setzte Dinge und Men- 


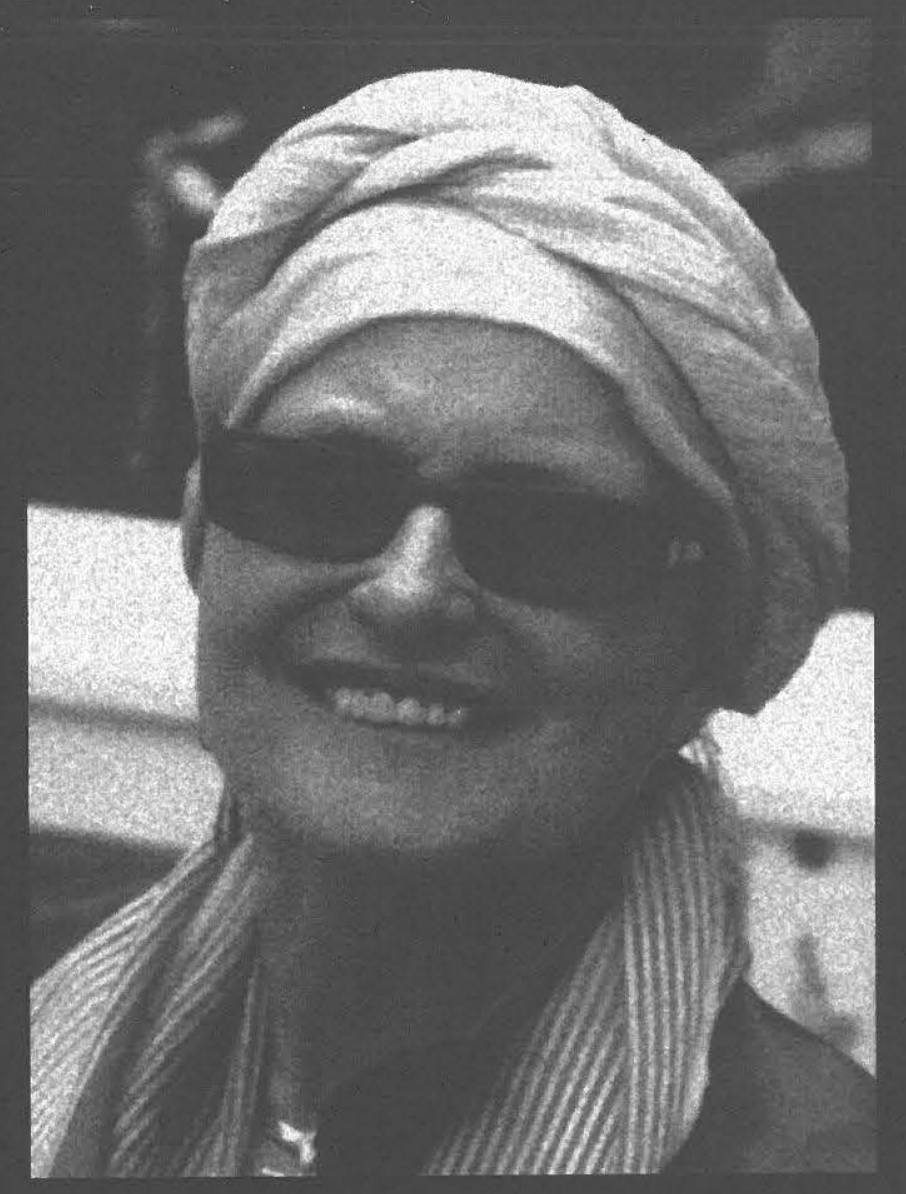

schen in Bewegung. Sie war keine Einzelkämpferin, sie vertraute auf Personen, spannte sie ein und holte das Beste aus ihnen heraus. Sie rief so schöpferische Initiativen ins Leben wie das Comenius-Projekt zu "Volksweisheiten über das Wasser» oder "Das Habitat Sevilla im Vergleich zum Habitat Mülheim», für die ihre Schïler wahre Meisterwerke schufen, auf Deutsch natürlich.

So war es nicht verwunderlich, dass Hiltrud auch Vorreiterin und Schlüsselfigur des Bilingualen Programms in Andalusien war. Das San Isidoro wurde das erste offentliche Gymnasium Andalusiens mit bilingualem Zweig Deutsch-Spanisch, und eine Referenz in Spanien. Sie schaffte es, dass das Schulamt zwei zusätzliche Planstellen schuf und ermunterte andere Fachschaften wie Geschichte, Kunst, Musik und Philosophie, sich diesem innovativen Projekt anzuschließen.

Seit Anfang der Neunziger Jahre war Hiltrud verantwortlich für die Deutsch-Didaktik der Pädagogischen CAP Kurse und gab DaF-Seminare am Departamento de Filología Alemana der Universität Sevilla. Hier hat sie Hunderten von Germanistik-Absolventen des Germanistik-Studiums der Universität Sevilla ihr didaktisches Rüstzeug mitgegeben. Ihre Saat ist in einer ganzen Generation von Deutschlehrenden in Andalusien aufgegangen, die sie wiederum an die nächste Generation weiter geben wird.

1994 gründeten wir gemeinsam die Asociación Andaluza de Germanistas AGA. In ihren Vorstandsfunktionen kämpfte sie unermüdlich für die Belange des Deutschen. Sie hat unzählige Fortbildungsmassnahmen organisiert und selbst durchgeführt, unser Verbandsblatt magazin mitherausgegeben, uns vor der Verwaltung vertreten und zahllose Anstöbe mehr gegeben.

Hiltrud war eine Vollblut-Pädagogin. Sie mochte Menschen, hatte Geduld und Verständnis und horte nicht auf, sich selbst und andere weiter zu bilden. Sie war kompetent, tatkräftig, grosszügig, herzlich, offen, immer hilfsbereit. Wenn irgendetwas im Argen lag, Hiltrud half aus der Klemme.

Die quantitative Situation des Deutschen im offentlichen Schulsystem hat sich in den langen Jahren kaum gebessert. Nur wenige können und wollen heute noch Deutsch unterrichten, da die andalusische Schulverwaltung einfach keine Stellen ausschreibt. Aber an Hiltrud hat es mit Sicherheit nicht gelegen. Sie hat alles getan, was in ihrer Macht stand, und das war mehr als viele Minister es leisten können.

Hiltrud war Karl-Valentin-Fan. Sie hat, zusammen mit ihrem Mann Pedro Álvarez, viele Werke des genialen Münchener Komikers ins Spanische übersetzt, eine wegen ihrer Schwierigkeit fast heroische Aufgabe, die auch zahlreiche spanische Theater-Auffuhrungen Valentins möglich gemacht hat (siehe die Rezension in diesem Magazin, Seite 72). Daher fände sie es sicher schön, wenn wir uns mit einem Schmunzeln verabschieden und mit Valentin sagen «Der Mensch ist gut, die Leute sind schlecht!" Hiltrud gehörte ganz sicher zur ersten Gruppe. 